\title{
Liquid Crystals as Lubricants
}

\author{
Nadezhda V. Usol'tseva * (iD) and Antonina I. Smirnova \\ Nanomaterials Research Institute, Ivanovo State University, Ermak str., 39, 153025 Ivanovo, Russia \\ * Correspondence: nv_usoltseva@mail.ru
}

Received: 31 October 2019; Accepted: 3 December 2019; Published: 9 December 2019

\begin{abstract}
The review summarizes the literature data and the authors' own research results on the application of liquid crystals in tribology. It has been shown that both thermotropic (calamitic, discotic, cholesteric) and lyotropic (surfactants, chromonics) mesogens as tribological additives are able to optimize the properties of lubricating compositions when introduced even at low concentrations to oils and greases. A wide possibility of varying the chemical structure of mesogens and studying the relationship between their structure and tribological properties can be used for the desired (programmed) change of the quality of tribotechnical processes. The synergism of the combined use of mesogenic esters of cholesterol and carbon nanostructures as additives in improving tribological properties has been established. The use of synthetic lubricants in biological systems still requires further research as the experimental results obtained on models of joint prostheses in vitro conditions are significantly worse than the results obtained in vivo. Considering the annual loss of billions of US dollars worldwide due to the low efficiency of friction processes in the industry and the resulting wear, liquid crystals and the systems based on them can be the most effective way to optimize these processes. The present review will be useful for researchers and industrialists.
\end{abstract}

Keywords: tribology; thermotropic and lyotropic liquid crystals; calamitic and discotic mesogens; biological fluids

\section{Introduction}

Long before the introduction of the term "tribology", which for the first time was used in 1966 [1,2] and combines a set of scientific and technological ideas about interacting surfaces when they move relative to each other, a number of phenomena displaying in this area were discovered. For example, in order to reduce friction, various oils and fats were empirically used. On the copy of the Egyptian kingdom fresco, one can see that in order to move the huge pharaoh statue, the surface in front of the sleigh on which the statue is placed is poured with liquid. Leonardo da Vinci (1452-1519) was the first to begin to formulate the basic laws of friction. The first reliable friction wear test was performed on gold coins by Hatchett (1760-1820), who compared the wear during the direct friction of coins and the friction with sand between them. For the first time, the graphic characteristics of the friction regime were obtained by Professor Stribeck (1861-1950) of the Royal Prussian Institute of Control (Berlin) [3]. It can be said that centuries passed before the field of science that is now called "tribology" was developed. It should be noted that the growth of interest in these issues occurred in the mid-1970s, when specialized centers were opened in different countries, and scientific societies such as the Society for Tribologists and Lubrication Engineers (STLE) in the USA and the Gesellschaft für Tribologie in Germany were established. At present, practically all technical universities have groups dealing with tribology problems.

The theory and practice of implementing tribological processes have attracted increasing attention as objects of interdisciplinary research that have a serious impact on the economies of developed countries. It was proven that the corresponding application of tribological principles in the industry 
and their practical realization can save from $1.0 \%$ to $1.4 \%$ of the total national product of the state due to wear reduction [4]. Obtaining the most efficient lubricants is not only a technological problem, it is also an important economic one, since half of the consumed energy is spent on friction [5].

In this paper, a critical analysis of the literature data and the authors' own results regarding the use of thermotropic and lyotropic mesogens in technical and biological systems as 'smart' materials that allow the development of new lubricants with programmable properties is presented.

\section{Surface Orientation in Tribology as a Special Case of Mesomorphism}

In recent years, researchers have been especially keen on boundary lubrication problems. This is due to the tightening of the operating conditions of friction lubrication units both in terms of loads and temperature conditions, energy and resource-saving needs, a rapid development of nanotribology [6], a complication of lubricating compositions [7], etc. Up to now, the generally accepted criteria that allow predicting the relationship between the chemical structure of lubricants (or tribological additives to lubricants) and their physicochemical properties have not been developed.

The main functions of lubricants are reducing the friction between contacting surfaces, distributing the temperature and pressure between surfaces, removing heat and wear products from the friction zone, and preventing corrosion of the surface layer of friction pairs.

New requirements for the optimization of friction processes caused due to technological progress, such as functioning at certain temperatures, reversible lubricating properties, thermal stability of mesophases, etc. demand to create new 'smart' lubricant materials and compositions with programmable properties. Liquid crystals are among these materials [8].

At present, there is no doubt that the presence of adsorbed ordered layers on interacting surfaces prevents their direct contact and leads to a significant reduction in friction and wear, while the chemical feature of the surface controls wear resistance. The near-surface boundary/interfacial layer of lubricant, oriented by the force field of the solid surface, forms an epitropic mesophase.

It was shown that the wear during the frictional interaction of solids decreases with the increasing of the optical anisotropy of the boundary layer formed by anisometric surfactant molecules [9]. If fatty acids are used as surfactants, then the orientation effect is most pronounced. The fact that mesogens, i.e., compounds that are capable of forming liquid crystal phase(s), can form surface-oriented layers attracted attention to them. They began to be considered as new lubricant materials or additives to lubricants, lubricoolants, and mineral oils. Already in 1936, V.K. Fredericks, an outstanding Russian researcher of liquid crystals, expressed the idea of the need for studies of the lubricating properties of liquid crystalline materials [10].

The first generalization of work in this direction occurred at a special 198th symposium of the American Chemical Society "Tribology and liquid crystal state" about 30 years ago [11]. The results of the work regarding the use of thermotropic and lyotropic mesogens or their additives in tribological processes were presented there. In fairness, it should be noted that in the USSR, such works at that time were also successfully carried out. The leader in this direction was Ivanovo State University, where in 1964 at the Department of Physics, the Laboratory of Liquid Crystals and Polymers was opened for the first time in the USSR after the Second World War. The presence of two scientific schools led by Professor V.N. Latyshev (who worked in the field of tribosystems) and Professor I.G. Chistyakov (who was the pioneer in the field of liquid crystals in USSR) predetermined the success of the Ivanovo scientific school in this direction [12-15].

The liquid crystalline (mesomorphic) state is a state of matter in which the degree of molecular order is intermediate between the long-range three-coordinate translational order (solid crystal) and the absence of the translational order (isotropic liquid) [16].

According to the formation conditions, there are thermotropic liquid crystal (LC) phases and lyotropic LC phases. The basic units of thermotropic LCs are organic molecules-mesogens, which satisfy special requirements [17]. Usually, they have an anisometric shape and combine flexible and rigid fragments. 
Lyotropic LCs are formed in binary or multicomponent systems containing water or other solvents. The building blocks of lyotropic mesophases are not individual molecules, but rather supramolecular ensembles, for example, micelles [18].

The characteristic structures and chemical properties of a large number of mesogens, i.e., substances exhibiting a liquid crystalline state, are collected in a special database named LiqCryst, which was created by Vill (Germany) [19].

The main classes of mesogens united by the form of their molecules are calamitic (rod-shaped) and discotic (disc-like) mesogens. Some of the LC phases formed by calamitic and discotic compounds are shown in Figure 1.

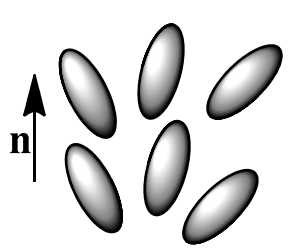

$\mathbf{N}$

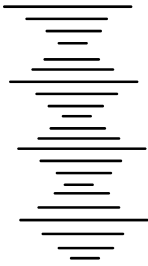

Ch

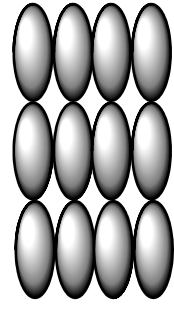

$\operatorname{SmA}$

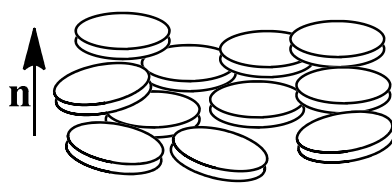

No

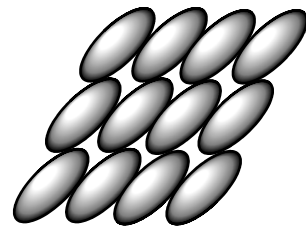

$\mathrm{SmC}$

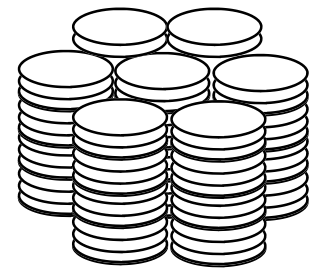

Col

Figure 1. Mesophases formed by calamitic and discotic mesogens: $\mathrm{N}-$ nematic phase, SmA-smectic A phase, SmC - smectic $C$ phase, $\mathrm{Ch}$-cholesteric phase, $\mathrm{N}_{\mathrm{D}}$ - discotic nematic phase, Col—columnar hexagonal ordered phase.

The study of liquid crystals at the empirical level occurred at the end of the 19th and the beginning of the 20th century, but later, a significant impetus to its further development gave the needs of electronics: the creation of information display screens, including computers, light emitting diodes, solar panels, etc.

Below, we review the main achievements associated with the established patterns on the influence of the chemical structure of mesogenic compounds on tribological processes.

\section{Thermotropic Mesogens in Tribology}

\subsection{Calamitic Mesogens}

To create new effective lubricants, it is important to understand the relationship between the chemical, supramolecular structure of thermotropic mesogens and the realization of their tribological properties.

A typical example of solving this task is the study of calamitic mesogens by varying their chemical structure. Examples of the compounds investigated in that work are presented in Table 1 [20]. 
Table 1. Calamitic mesogens studied by Cognard [20].

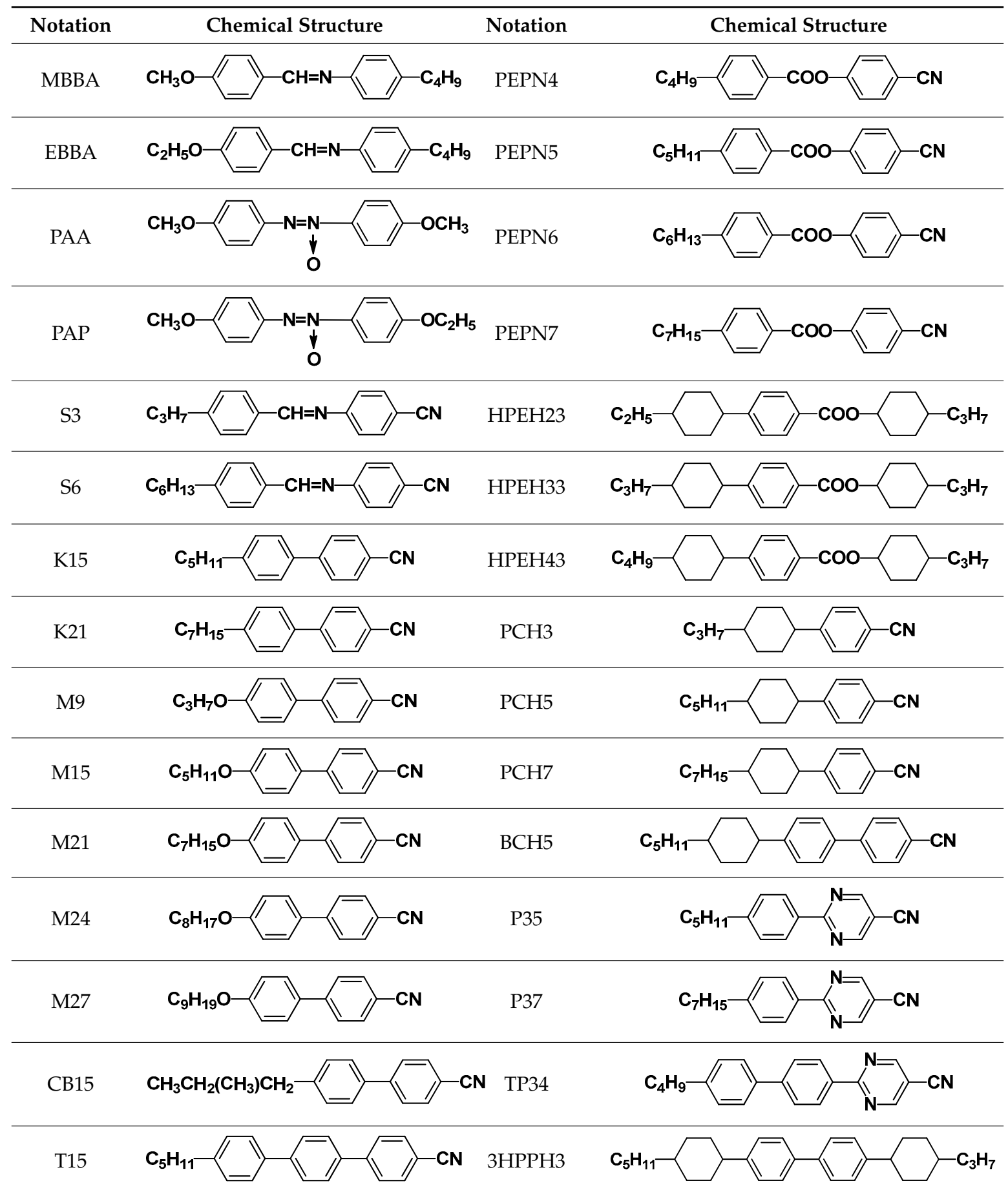

Thus, Mori and Iwata [21] considered three representatives of calamitic mesogens: cyanobiphenyls, alkoxycyanobiphenyls, and alkylcyanophenylcyclohexyls with a variation of the length of the aliphatic chain $\mathrm{C}_{n} \mathrm{H}_{2 n+1}(n=5-12)$ (Figure 2). 


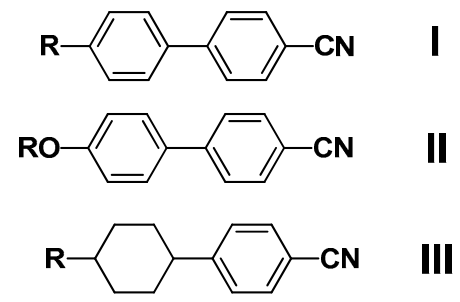

Figure 2. Calamitic mesogens reported in [21]: I-alkylcyanobiphenyls, II—alkyloxycyanobiphenyls, and III-alkylcyanophenylcyclohexyls; $\mathrm{R}$-alkyl group $\left(\mathrm{C}_{n} \mathrm{H}_{2 n+1}\right), n=5-12$.

Tribological tests were carried out in the temperature range from 20 to $60^{\circ} \mathrm{C}$ on a device with two rotating cylinders at a load of $735 \mathrm{~N}$. The rotation speed of $220 \mathrm{rpm}$ was constant for one cylinder and varied from 220 to $350 \mathrm{rpm}$ for the other one. The data obtained were compared with each other and with the results of similar studies obtained for mineral oils. It was found that at the same rotation speeds, the mesogens form thicker layers compared to synthetic oils, but their friction coefficients are lower than those of synthetic oils. When studying the dependence of the friction coefficient on the chemical structure of mesogens, it was shown that this parameter strongly depends on the structure of the rigid fragment of the molecules. The lowest friction coefficient among the studied compounds was detected for cyanobiphenyls; it equals 0.035 . If one of the phenyl groups is replaced by a cyclohexyl fragment (compound III), then the friction coefficient increases to 0.045 . The authors concluded that the flatter molecular structure of compound I (compared with compound III) positively affects the friction coefficient. Replacing the alkyl group (compound I) with an alkoxy group (compound II) also leads to a slight increase in the friction coefficient (up to 0.04). At the same time, the value of the friction coefficient practically did not depend on the number of carbon atoms in the aliphatic chain in the corresponding homological series. The authors drew attention to the fact that the coefficient remained practically unchanged, although the viscosity of mesogens increased with an increase in the number of carbon atoms in the alkyl chain. There was also no pronounced dependence of this parameter on temperature: the study affected only those temperature regions at which thin layers without shear conditions showed both mesomorphic and isotropic liquid states. Apparently, the ability of mesogenic material to form special "epitropic" structures under shear conditions plays the leading role in tribological effects in these cases, in particular, to orient themselves in a special way. The data of FT-IR spectroscopy under shear conditions prove that the rigid cyanobiphenyl fragments of molecules are oriented parallel to the shear plane [21].

Nakano's studies [22] on the variation of the friction coefficient by using alkylcyanobiphenyls, alkoxycyanobiphenyls, and other calamitic mesogens are also in the same line. The main conclusions drawn for the compounds indicated in Table 1 can be represented as follows: (1) the higher the nematic - isotropic phase transition temperature $\left(\mathrm{T}_{\mathrm{NI}}\right)$, the lower the friction coefficient; (2) the lowest friction coefficient is observed in a mixture of nematogens with high $\mathrm{T}_{\mathrm{NI}}$ values and a high orientation degree [20]. These data were in good agreement with previous studies on the tribological properties of the eutectic mixture of N-(4-Methoxybenzylidene)-4-butylaniline (MBBA) and $N$-(4-Ethoxybenzylidene)-4-butylaniline (EBBA) in comparison with the tribological properties of both aviation oil (MS 20 aviation oil) and vaseline oil (Vaseline oil) [20].

Amann and Kailer [23] synthesized a number of calamitic compounds with intramolecular hydrogen bonds and studied them as potential materials for lubrication processes. They investigated their viscosity properties at different temperatures, taking into account the important role of this parameter in tribology. It was found that an increase in molecular weight correlates with an increase in viscosity. For all compounds, elongation of the alkyl chain also increases viscosity. Reducing the size of the molecules reduces the friction coefficient, but the running-in period becomes longer.

Waźyńska and Okowiak [24] devoted their study of calamitic mesogens as lubricants to the relationship between the type of the formed LC phase and tribological properties. They studied compounds exhibiting 
smectic A, B, and E phases, as well as the nematic phase (Figure 3). Pure individual mesogens as well as mixtures of smectics with nematic mesogens were used.
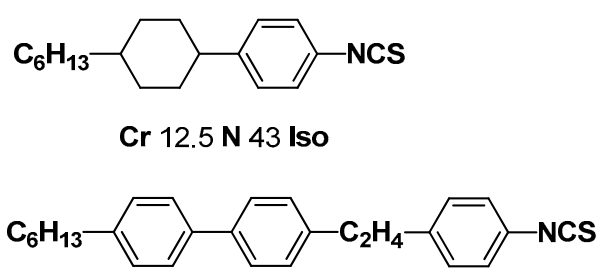

Cr 58 N 136 Iso

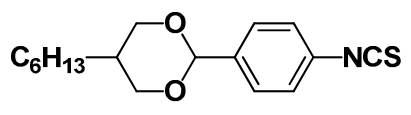

Cr 34.5 SmA 79 Iso

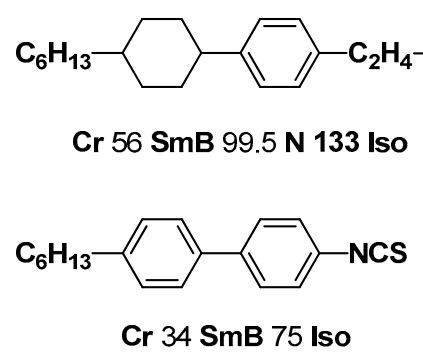

6CHBT

6BTPE

6DBT

6CHBTPE

6BT

Figure 3. Molecular structures, phase transition temperatures (given in ${ }^{\circ} \mathrm{C}$ ), and the reference designations of mesogens described in [24].

The main objective of the work was to determine the orientation of mesogens on the surface of steel samples. In the 'ball-disk' geometry using the tribological tester T-11, the friction forces, wear, and friction coefficient were studied at the following conditions: load $20,30,40,50 \mathrm{~N}$, shear rate $0.1 \mathrm{~m} / \mathrm{s}$, and test time $900 \mathrm{~s}$. An important result obtained in this work was that the smallest weight loss was observed when mesogenic mixtures exhibiting a nematic phase (compared with smectic phases) were used at all applied loads.

The friction coefficients values were obtained from 900 points depending on the load for mesogens in different phases and for paraffin oil. The obtained data showed that all the studied nematic phases showed a decrease in the friction coefficient with increasing load.

In this case, the nematic phase in comparison with all studied smectic phases showed the lowest friction coefficient. It is interesting to note that the mesogen mixture being in the smectic $\mathrm{B}$ phase initially also had a rather low friction coefficient, but it grew with the load increase, and at $50 \mathrm{~N}$, it became the largest among all the studied smectics. The dependence of the friction coefficient on the load was also noted for mixtures with smectic A and smectic E phases. The authors tried to analyze the obtained data from the point of view of the chemical structure of the mesogenic compound. It was concluded that the type of mesophase does not influence the tribological properties as much as the chemical structure of the calamitic mesogen and especially the length of its rigid fragment. In this case, the polar groups of mesogen molecules are adsorbed on the surface of triboconjugation elements, the molecules obtain the perpendicular orientation on the steel surface, and thus, the resistance to movement is reduced. It has been shown that this adsorption phenomenon depends mainly on the chemical structure of compounds [24].

\subsection{Chiral Mesogens}

Cholesteric (chiral) mesogens represent another type of calamitic molecules. Cholesteric liquid crystals (CLCs) have excellent tribological characteristics (exceeding those of conventional calamitic 
mesogens), due to which they are able to reduce the friction coefficient and wear during the friction process.

From a physical point of view, such behavior can be explained by the fact that upon friction, the polymolecular layers of calamitic mesogens and surfactants are transformed into monomolecular ones. This transformation leads to an abrupt increase in shear resistance and has a negative effect on the wear of mating parts. In contrast, cholesteric interfacial layers do not have this disadvantage, because they form a stack of nematic layers where the upper and lower layers are adhesively bonded to the friction surfaces. At a shift, the molecules of nematic layers can freely move (slide) relative to each other. In addition, the cholesteric boundary phase is characterized by the possibility of orientation of its molecules by microrelief grooves [25].

The influence of the phase state of cholesteric mesogens (Figure 4, their phase transition temperatures are presented in Table 2 [26]) on the friction coefficient was studied by Syrbu and coauthors [27]. The studies were performed using the laboratory tribometer TLPF1 in the conditions of boundary friction during reciprocating movements.

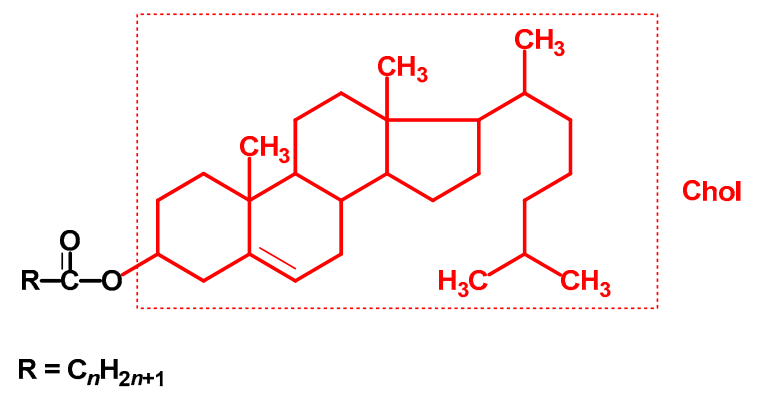

Figure 4. Structural formula of cholesterol derivatives.

Table 2. Cholesterol derivatives used as additives in [27] and their mesomorphic properties [26].

\begin{tabular}{|c|c|c|c|}
\hline Notation & Compound & Molecular Weight & Phase Transitions $\left({ }^{\circ} \mathrm{C}\right)$ \\
\hline$X-19$ & Chol- $\mathrm{COOH}$ & 414 & Cr 97.5 Iso \\
\hline$X-26$ & Chol-Cl & 405 & Cr 97.0 Iso \\
\hline$X-4$ & Chol- $\mathrm{COOC}_{4} \mathrm{H}_{9}$ & 470 & Cr 93 Ch 101.5 Iso \\
\hline$X-6$ & Chol- $\mathrm{COOC}_{7} \mathrm{H}_{15}$ & 512 & Cr 110 Iso \\
\hline$X-5$ & $\mathrm{Chol}_{-} \mathrm{COOC}_{9} \mathrm{H}_{19}$ & 540 & Cr 85.5 Ch 92.5 Iso \\
\hline $\mathrm{X}-18$ & Chol-COOC ${ }_{10} \mathrm{H}_{21}$ & 554 & Cr 92.5 Iso \\
\hline$X-20$ & Chol- $\mathrm{COOC}_{12} \mathrm{H}_{25}$ & 582 & Cr $63.5 \mathrm{Sm} 78.8 \mathrm{Ch} 84.8$ Iso \\
\hline$X-28$ & Chol- $\mathrm{COOC}_{14} \mathrm{H}_{29}$ & 610 & Cr $70 \mathrm{Sm} 78.3$ Ch 82.9 Iso \\
\hline$X-37$ & Chol-COO- $\left(\mathrm{C}_{6} \mathrm{H}_{4}\right)-\mathrm{C}_{8} \mathrm{H}_{17}$ & 602 & Cr 138 Sm 171.5 Ch 220.5 Iso \\
\hline$X-68$ & Chol-COO- $\left(\mathrm{C}_{6} \mathrm{H}_{4}\right)-\mathrm{C}_{12} \mathrm{H}_{25}$ & 658 & Cr 128.5 Sm 179.5 Ch 200.5 Iso \\
\hline Chol- & $\mathrm{C}_{27} \mathrm{H}_{45}$ & 369 & \\
\hline
\end{tabular}

It was found that during friction within the mesophase existence temperature range, the friction coefficient decreases with increasing temperature. Such behavior was not observed for non-mesogenic cholesterol esters, i.e., with the temperature increase, the decrease of the friction coefficient was absent. In the isotropic liquid region of mesogenic compounds, the mesogens with higher molecular weight have a lower friction coefficient. The best lubricating properties (the lowest friction coefficient $\mu=0.06-0.08$ ) were shown by cholesterol ester $\mathbf{X}-68$, which has the widest mesophase range.

Non-mesogenic cholesterol derivatives X-19 and X-26, which do not form mesophases, have similar melting points and molecular weights. However, their influence on the friction coefficient is 
different: for X-26, the friction coefficient does not depend on temperature, while for X-19, it gradually increases with increasing temperature from 0.08 to 0.13 . The authors assume that this difference can be explained by the chemical activity of the substituents that comprised the compound X-26. Analysis of the molecular weight influence on the properties of the studied CLCs was performed. It was revealed that at the temperature of $150^{\circ} \mathrm{C}$, the friction coefficient of compounds with a molecular weight less than 550 a.m.u. does not depend on their molecular weight value. Above 550 a.m.u., an increase in the molecular weight of the compound results in a decrease of the friction coefficient proportionally to the molecular weight. This dependence was also described by Hardy [28] for boundary friction. The data obtained confirm the importance of the viscosity of systems in tribological processes. In the mesophase, viscosity increases, while in the isotropic liquid phase, it decreases.

\subsection{Mesogens as Additives to Lubricants and Greases}

Since liquid crystal materials are quite expensive to produce, the attention of researchers was attracted to the possibility of their use as additives (lubricant additives) to lubricants (oils and greases) [5]. It should be at once noted as the expected result that the friction coefficient of oil systems with mesogen is higher than that of individual mesogens.

The use of CLCs as additives in tribological processes raised the question of their compatibility with oils. The analysis of solubility of cholesterol esters in medical Vaseline oil, polymethylsiloxane fluid (PMS-200), and engine oil M-12G 1 revealed three groups of systems: (1) a true solution of CLC in oil, (2) the heterogeneous system 'CLC crystals in oil', and (3) a thickened suspension of small crystals in oil. Therefore, the second group is characterized by the partial solubility of mesogens in oil, and in the third group, the solubility of mesogens in oil below their melting point is absent. The authors [25] attribute this to the dimensional value of the intermolecular interaction between 'mesogen-mesogen' and 'mesogen-oil'. The rheological properties of oils change with the introduction of CLCs: viscosity increases over the entire temperature range. At the same time, the viscosity of the synthetic fluid PMS-300 increases to a greater extent than that of Vaseline oil.

As for the tribological properties of oils, a decrease in the friction coefficient is observed when CLCs are introduced into the oil. It should be noted that the minimum wear does not always correspond to the lowest friction coefficient. Nevertheless, there is a tendency to improve the tribotechnical characteristics of oil solutions containing mesogens with higher molecular weight $(X-7, X-5$, and $X-16)$, which have lower transition temperatures from crystalline phase to the liquid crystalline phase. At the same time, with an increase of the alkyl radical length of mesogens, an increase in the wear value is observed in comparison with Vaseline oil [25].

The kinetics of the friction coefficient and the surface topography were studied by Kupchinov B.I. et al. [29] when the content of mesogen X-16 in Vaseline oil was in the concentration range of $0.5-9.0 \mathrm{wt} \%$ (slip velocity was $0.5 \mathrm{~m} / \mathrm{s}$, load was $3.5 \mathrm{MPa}$ ). It was found that in general, the introduction of X-16 leads to a decrease in the friction coefficient. However, the additive concentration affects the time that it takes to reach this value from the onset of dynamic contact: an increase in concentration leads to a decrease in this time. Moreover, when lubricant contains high mesogen content, there are probably enough mesogen molecules to form a layer that can hide the microroughness of the friction surface.

Due to that, Bermudez et al. [30] carried out studies on the influence of the molecular structure features of calamitic mesogens: homologues of 4,4'-dialkyl- and dialkyloxybenzenes, 4,4'-dialkylazoxybenzenes, and cyanoaryls, which were used as additives to commercial oils. The 'finger-disk' geometry of the tribometer was used at various temperatures and additive concentrations. In this case, neither the temperature variation of the phase transitions of mesogens, nor the difference in viscosity had a significant effect on the magnitude of friction. It is important to note that for all 14 compounds studied, the addition of only $1 \%$ of mesogen to two different base oils significantly reduced the friction coefficient of steel. The wear degree in the contacts of 'steel-steel' and 'steel-aluminum' pairs also decreased with the addition of these mesogens to base oils. 
A wide range of tribological studies was carried out using as additives the cholesterol esters (CLC), which exhibit a chiral nematic $\left(\mathrm{N}^{*}\right)$ phase [25,31]. Vekteris and Mokshin [31] studied boundary lubrication processes using industrial mineral oil I-40A with the additives of four homologues of cholesterol esters (2 vol. \%): valerianic $\left(\mathrm{C}_{4} \mathrm{H}_{9}\right)$, caproic $\left(\mathrm{C}_{5} \mathrm{H}_{11}\right)$, myristic $\left(\mathrm{C}_{13} \mathrm{H}_{27}\right)$, and stearic $\left(\mathrm{C}_{17} \mathrm{H}_{35}\right)$. Data obtained were compared with parameters of pure mineral oil without additives. The tests were conducted in conditions of boundary lubrication. The roughness of the cylinder before each experiment was $R a=2.5 \mu \mathrm{m}$. The cylinder constantly rotated at a speed of $545 \mathrm{rpm}$ (with a peripheral speed of $v=1.4 \mathrm{~m} / \mathrm{s}$ ). The load on a segment was $1000 \mathrm{~N}$.

Firstly, it was found that only the three studied homologues are completely soluble in mineral oil at a concentration of 2 vol. \% (stearyl ether of cholesterol crystallizes in industrial oil). Therefore, additional melting of the mixture was necessary before use. Tests have shown that all the LC additives of this series positively influenced the antifriction properties of mineral oil. Chiral mesogens with the highest molecular weight (stearate and myristate of cholesterol) are the most effective: when they were used as additives to industrial oils, the friction coefficient for the 'steel-steel' tribological system decreases by 1.12 times compared to pure industrial oil (namely, from 0.105 to 0.094 ) [31].

The works of Latyshev et al. [32] are logically related to the above-mentioned data. They concern the rheological properties of lubricants with CLC additives. Based on the view that studies of flow curves can serve as a means of revealing the internal structure of anisotropic liquid and its change with varying external conditions [25], the authors studied the rheological properties of a number of cholesteryl esters of alkyl, alkyloxy, and alkyloxybenzoic acids, as well as cholesterol chloride as an additive to two types of base oils. They investigated the solubility of these additives and then the rheological properties of compositions. It was shown that cholesteryl esters of undecyl and oleic acids dissolve well in base oils, while cholesteryl esters of benzoic acids have limited solubility. It was also found that the introduction of the CLC additives into low-viscous oils influences their viscosity by an average of $10 \%$. The higher the degree of the influence, the less the amount of other additives inserted into the original oil. For more viscous gear oils, the introduction of new additives has practically no effect on rheological properties [32].

The study results of the temperature effect on the friction coefficient of $1 \%$ solutions of cholesteric liquid crystals in industrial oil I-20 are presented in [27]. It was established that at temperatures below $100{ }^{\circ} \mathrm{C}$, the friction coefficient of solutions is practically independent on temperature, and it is approximately the same for the different studied compounds $(\mu=0.13 \ldots 0.14)$. However, with a further temperature increase, a linear growth in the friction coefficient begins, and the values of $\mu$ reach $0.17 \ldots 0.18$. The authors explain the obtained pattern by the formation and temperature destruction of the adsorbed boundary-lubricating layer formed by CLC molecules on rubbing surfaces. At low temperatures, a chemisorption bond occurs between the molecules of nanomaterial and the surface, which gives stability to the film. At a certain critical temperature, the adsorption bond between the CLC molecules and the surface breaks down, which results in an increase in the friction coefficient. The critical temperature value depends on the structural composition of the nanomaterial. For all compounds with the-COO-group, this temperature is in the range between 125 and $130{ }^{\circ} \mathrm{C}$, and for cholesterol chloride, it is between 110 and $115^{\circ} \mathrm{C}$.

Unlike isotropic lubricating oils, plastic lubricants (PLs) are structured colloidal systems. The rheological characteristics of the 'PL-CLC' systems were studied by Berezina et al. [33]. In this work, Litol-24 was used as the PL material, and CLCs were represented by five cholesterol esters having aliphatic substituent with a varying number of carbon atoms $(n=8-17)$. Additive concentrations were varied from 0.5 to $5.0 \mathrm{wt} \%$. The introduction of CLC compounds in all cases led to a decrease in yield strengths. The relationship between shear stress and shear rate was well described by the Shvedov-Bingham model $[33,34]$. It was found that the introduction of CLC additives changes the rheological properties of the system, which the authors attribute to the formation of a less durable spatial structure. The authors note as characteristic rheological data that at low shear rates, kinks in the course of the curves are observed, indicating structural changes in the system. When additives are added, the 
viscosity of systems is significantly reduced. Different flow mechanisms were presented at different sections of the rheological curve, which corresponded to the Rebinder concept [35]. According to the flow curves, the studied samples obeyed the Casson model and regression coefficients decreased with the increasing shear rate. A change in the rheological properties should have a beneficial effect on the tribological properties of LSs. It was found that the introduction of even a very small amount of additive leads to a decrease in the effective viscosity of systems by several tens of times. The authors concluded that by introducing small amounts of additives (cholesterol esters), it is possible to achieve a sharp change in the properties of the lubricating composition.

With the aim to optimize the antifriction and antiwear properties, the structure of classical cholesterol esters was modified by fluorination [8]. The introduction of fluorinated (perfluoroalkyl) chains enhanced the polarity of compounds due to the C-F bond. This should have led to a change in the mesophase existence temperature and better adsorption of the material on the metal surface. Four cholesterol esters were synthesized (Figure 5).
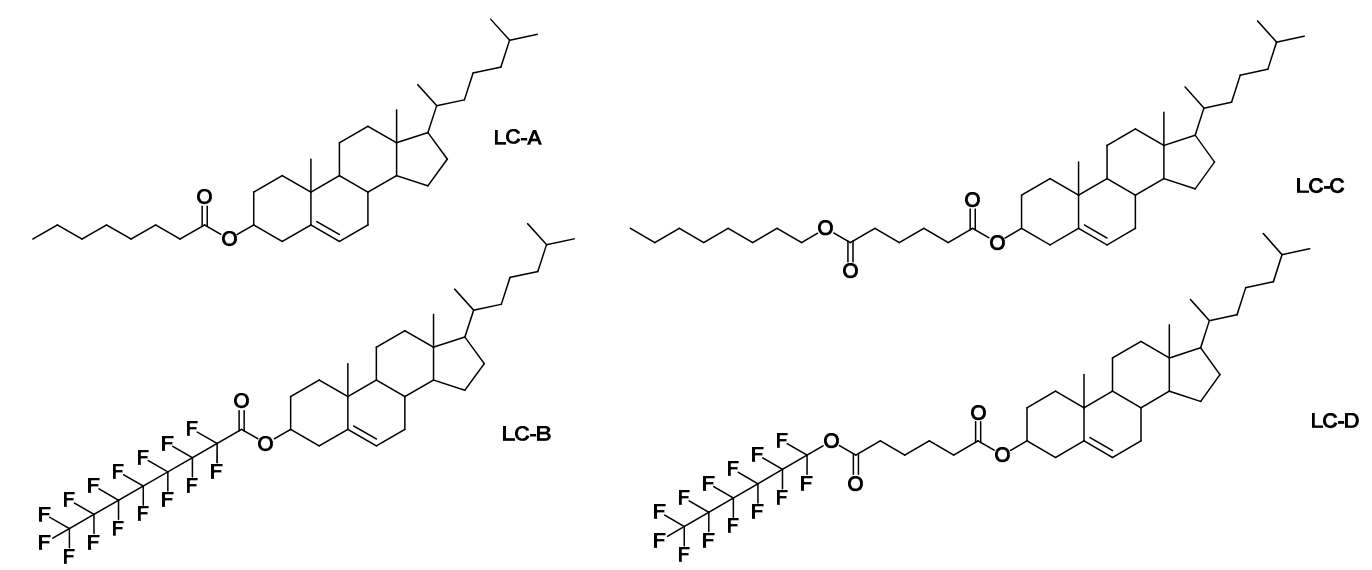

Figure 5. T Fluorinated cholesterol esters (LC-B, LC-D) and their non-fluorinated analogues (LC-A, LC-C) studied by Gao [8].

It was found that among the four synthesized compounds, three showed mesomorphism monotropically, and only one compound (LC-D) showed enantiotropically. The region of the mesophase existence was expanded. The tribological data obtained for the systems of these mesogens with mineral oil using BMI Tribolab indicate fairly good tribological properties for all the compounds. However, the LC-D compound, which has the largest range of mesophase existence, showed the best tribological properties. The authors associate it with an additional buffer layer in the oil film composition, which is formed by fluorinated substituents. It is very important that within the mesophase existence range, the dispersion of LC in mineral oil significantly reduces the friction coefficient. The authors believe that this feature can be applied for the development of medical equipment, equipment for bionics, etc.

A large cycle of works on the tribological properties of cholesteric mesogens and their application was carried out in Belarus and summarized in a monograph [36].

Our own studies on the rheological and tribotechnical properties of industrial oil systems with CLC additives (cholesteric esters of carbonic acid: stearic $\mathbf{X}-\mathbf{7}$, propionic $\mathbf{X - 1 0}$, oleic $\mathbf{X}-\mathbf{1 6}$, and tridecanoic $\mathbf{X - 2 0}$, the concentrations of mesogens are shown in Table 3) revealed that $\mathbf{X}-\mathbf{7}$ and $\mathbf{X - 2 0}$ are good antiwear additives [37].

The search for smart materials led us to the idea of considering the possibility of an additional introduction to CLCs of carbon nanostructures, which are also known to affect the tribological processes [38], and then use the 'CLC-carbon nanostructure' system as a complex lubricant additive to industrial oil. It turned out that the introduction of multi-walled carbon nanotubes (MWCNT) in micro quantities in relation to the total volume of lubricant (0.0001 wt \%) in compositions with X-7 or X-20 CLC improved the antifriction qualities of the whole (oil) system [37]. 
Table 3. Compositions of two- and three-component systems ${ }^{1}$ [39]. MWCNT: multi-walled carbon nanotubes.

\begin{tabular}{cc}
\hline Two-Component Systems & \multicolumn{1}{c}{ Three-Component Systems } \\
\hline \multicolumn{2}{c}{ Industrial oil I-20A (base) with additives: } \\
\hline X-7 $(2 \%)$ & X-7 $(2 \%)+0.0001 \%$ of MWCNT \\
\hline X-10 $(2 \%)$ & X-10 $(2 \%)+0.0001 \%$ of MWCNT \\
\hline X-16 $(2 \%)$ & X-16 $(2 \%)+0.0001 \%$ of MWCNT \\
\hline X-20 $(2 \%)$ & X-20 $(2 \%)+0.0001 \%$ of MWCNT \\
\hline${ }^{1}$ Concentrations are given in wt $\%$, names of CLCs are given in the text.
\end{tabular}

In addition to the thermotropic mesomorphism and temperature range of the LC phase, the most important physical parameters for the use of cholesteric mesogens in tribology are their rheological characteristics. The flow curves of pure CLCs and 'CLC-MWCNT' dispersions were obtained at the temperatures of smectic A phase (SmA), chiral nematic $\left(\mathrm{N}^{*}\right)$, and isotropic (Iso) phases with the variation of shear rates between 0.01 and $3000 \mathrm{~s}^{-1}$ (Figure 6). The rheological properties of the samples under the conditions of constant shear rate and in the low-amplitude oscillatory deformation mode were studied using a Physica MCR301 rotational rheometer (Anton Paar, Austria). With the aim of creating smart materials for tribological processes, three-component systems containing not only an oil base, but also cholesteric LCs with the addition of nanoparticles were studied. Performing this task, we considered the possibility of a positive (synergetic) effect in the process of friction, since carbon nanostructures (CNSs) contribute to an increase in the thermal conductivity of systems. In addition, they are resistant to high mechanical loads and in some cases reduce the friction coefficient and wear rate of friction pairs $[38,39]$.

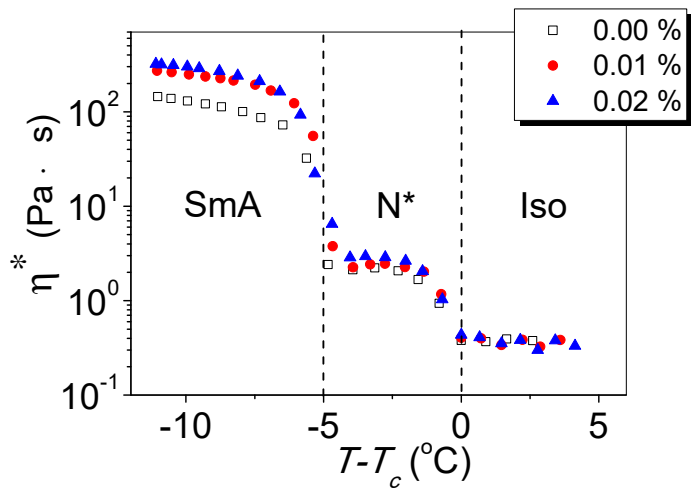

(a)

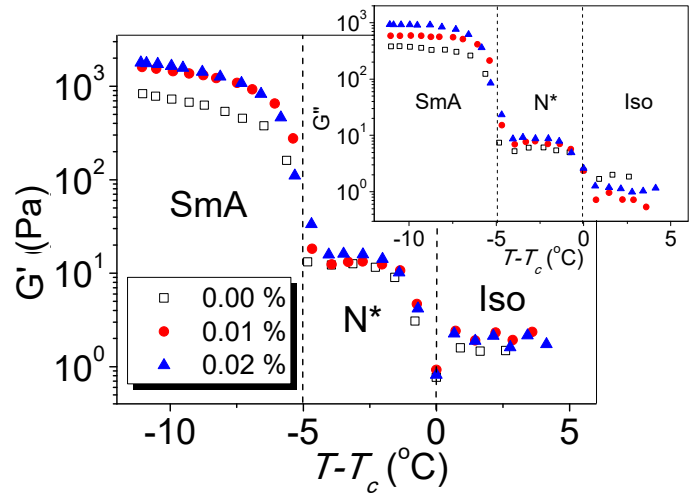

(b)

Figure 6. Temperature dependences of complex viscosity (a) and dynamic modules (b) of X-15 and its compositions with MWCNTs [39].

The effect of dispersed multi-walled carbon nanotubes (MWCNTs) (material "Taunit-M", OOO NanoTekhTsentr, Tambov, Russia) on the mesomorphic and rheological properties of three mesogenic cholesterol derivatives, $\mathrm{R}=\mathrm{CH}_{3}\left(\mathrm{CH}_{2}\right)_{7} \mathrm{CH}=\mathrm{CH}\left(\mathrm{CH}_{2}\right)_{7}$ - (Tekon-20), $\mathrm{R}=\mathrm{CH}_{3}\left(\mathrm{CH}_{2}\right)_{11}-(\mathrm{X}-20)$ and $\mathrm{CH}_{3}\left(\mathrm{CH}_{2}\right)_{12}-(\mathbf{X}-15)$, was studied in [39]. It was found that the introduction of MWCNTs into the CLC matrix (at concentrations of $0.01-0.04 \mathrm{wt} \%$ ) extends the temperature range of the mesophase.

The textures of the 'CLC-MWCNT' dispersions are identical to the individual CLCs, but when cooled to the crystalline phase, the polygonal texture of the dispersion becomes striated as "fingerprints" (Figure 7) [39] (i.e., there is the preservation of chirality by the "memory effect" type [40]). 


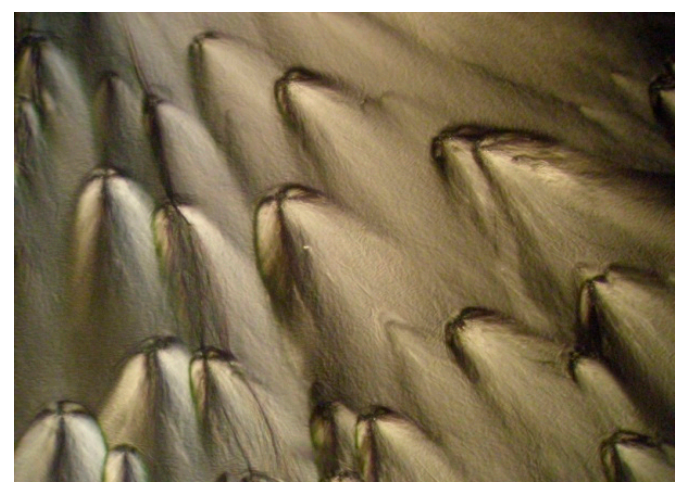

(a)

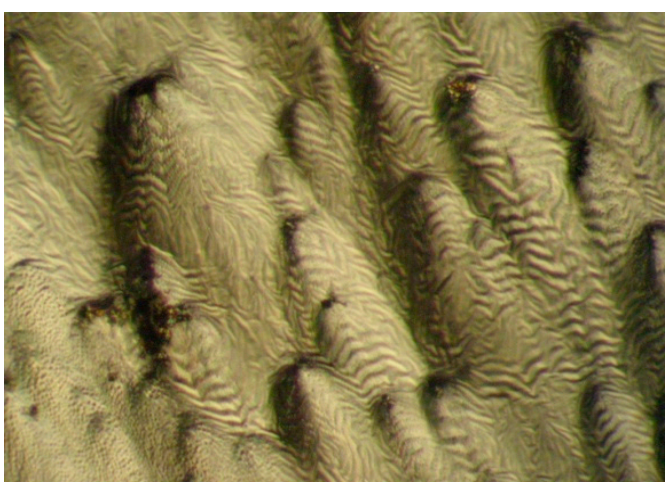

(b)

Figure 7. Micrographs of the polygonal texture of the crystalline phase of cholesteric liquid crystal (CLC) samples: (a) individual compound X-20, (b) composition X-20/MWCNT (0.01 wt \%), on cooling, crossed polarizers, $\times 250$ [39].

The introduction of MWCNTs (with a concentration of $\leq 0.02 \mathrm{wt} \%$ ) into the studied CLC (Figure 6) does not affect the complex viscosity of the resulted system in the isotropic phase, but increases $\eta^{*}$ by $25 \%$ in the $\mathrm{N}^{*}$ phase and increases the complex viscosity approximately twofold in the SmA phase.

The dynamic moduli of the composition respond to the introduction of MWCNTs as follows: the value of the elastic modulus $G^{\prime}$ increases and the viscosity modulus $G^{\prime \prime}$ decreases in the isotropic phase. Probably, in the isotropic phase, the additive particles form a percolation network.

Analysis of the temperature dependence of dynamic modules showed an increase of $G^{\prime}$ and $G^{\prime \prime}$ values by $\sim 25 \%$ in the $\mathrm{N}^{*}$ phase and an increase by $\sim 2.5$ times in the SmA phase. With an increase in the deformation frequency from 0.01 to $20 \mathrm{~Hz}$, the complex viscosity $\eta^{*}$ of CLC decreases by more than two orders of magnitude, and the storage and loss moduli increase approximately by twofold [41].

The tribological characteristics of two-component systems 'industrial oil I-20A-CLC', as well as three-component systems containing the industrial oil I-20A and the complex additive 'CLC-MWCNT', were presented in [39]. The studied CLCs were cholesteryl stearat (X-7), cholesteryl propionate (X-10), cholesteryl oleate (X-16), and cholesteryl tridecylate (X-20); they are listed in Table 4 along with concentrations of compositions.

The wear parameters (the area of the ball wear spot and the width of the wear of the roller track) were obtained. The experimental results are presented in Table 4 .

Table 4. Experimental conditions and data of tribological tests [39].

\begin{tabular}{|c|c|c|c|c|c|}
\hline \multirow{2}{*}{ Sample } & \multicolumn{2}{|c|}{ Temperature $\left({ }^{\circ} \mathrm{C}\right)$} & \multirow{2}{*}{$\begin{array}{l}\text { Wear of the } \\
\text { Roller (mm) }\end{array}$} & \multirow{2}{*}{$\begin{array}{l}\text { Area of the Ball } \\
\text { Wear Spot (mm) }\end{array}$} & \multirow{2}{*}{$\begin{array}{c}\text { Friction } \\
\text { Coefficient (f) }\end{array}$} \\
\hline & Start & End & & & \\
\hline Industrial Oil I-20A & 19 & 50 & 0.35 & 0.110 & 0.051 \\
\hline $\mathrm{I}-20 \mathrm{~A}+\mathrm{X}-7$ & 22 & 55 & 0.30 & 0.106 & 0.088 \\
\hline $\mathrm{I}-20 \mathrm{~A}+\mathrm{X}-7$ + MWCNT & 19 & 51 & 0.525 & 0.280 & 0.046 \\
\hline $\mathrm{I}-20 \mathrm{~A}+\mathrm{X}-20$ & 30 & 61 & 0.275 & 0.102 & 0.064 \\
\hline $\mathrm{I}-20 \mathrm{~A}+\mathrm{X}-20+\mathrm{MWCNT}$ & 19 & 49 & 0.50 & 0.165 & 0.046 \\
\hline $\mathrm{I}-20 \mathrm{~A}+\mathrm{X}-10$ & 19 & 48 & 0.625 & 0.298 & 0.051 \\
\hline $\mathrm{I}-20 \mathrm{~A}+\mathbf{X}-\mathbf{1 0}+\mathrm{MWCNT}$ & 21 & 56 & 0.60 & 0.306 & 0.088 \\
\hline $\mathrm{I}-20 \mathrm{~A}+\mathrm{X}-16$ & 24 & 54 & 0.60 & 0.158 & 0.088 \\
\hline $\mathrm{I}-20 \mathrm{~A}+\mathrm{X}-16+\mathrm{MWCNT}$ & 24 & 54 & 0.575 & 0.108 & 0.076 \\
\hline
\end{tabular}


The performed studies of the rheological and tribotechnical properties of the industrial oil with the addition of a number of CLC (see Table 4) showed that X-7 and X-20 are good antiwear additives. Three-component systems of the industrial oil with 'X-7-MWCNT' and 'X-20-MWCNT' additives showed good antifriction properties [39].

The influence of structural features of carbon nanoparticles (CNPs) (namely, shungite nanocarbon, $\mathrm{Sh}$ ) on the rheological properties of cholesteric mesogen (cholesterol tridecylate, $\mathbf{X}-20$ ) were analyzed after studying the rheological characteristics of ' $\mathrm{X}-\mathbf{2 0}$-Sh' binary systems (concentrations of Sh were $0.005,0.01$, and $0.02 \mathrm{wt} \%$ ) [42].

Based on the experimental data on the thermodynamic and the rheological characteristics of the CLC-Sh over the temperature range of the existence of SmA and $\mathrm{N}^{*}$ phases and isotropic liquid, as well as a comparison of the results with those previously published for the CLC-MWCNT systems [38], we revealed the general tendency of the carbon nanoparticle concentration to have an insufficient effect on the temperature range of the $\mathrm{N}^{*}$ phase existence and on the expansion of the SmA phase temperature range (by $\sim 10{ }^{\circ} \mathrm{C}$ at $0.02 \mathrm{wt} \%$ of Sh). Furthermore, both composites exhibited an increase in the elastic modulus $\mathrm{G}^{\prime}$ by at least $25 \%$ in the $\mathrm{N}^{*}$ phase.

With regard to viscosity, the CLC-Sh composites demonstrate a decrease in value compared to the CLC-MWCNT systems [39]. The elasticity of the system in the SmA phase in the presence of Sh was also decreased twofold with the increasing filler content, while the introduction of MWCNTs led to an approximately 2.5-fold increase in the elastic modulus.

The results of tests of the CLC system with Sh were quite interesting and revealed a decrease in the viscosity of the composites over the ranges of high strain rates at which the lubricants are used. The later evidences that one can vary the properties of the lubricant system by adding various types of carbon nanostructures. This is in good agreement with the data of [43].

\subsection{Discotic Mesogens in Tribology}

Along with calamitic mesogens, in recent years, discotic (disc-like) mesogens [44] have been studied as lubricants.

Discotic mesogens form three main types of thermotropic mesophases: columnar (Col), discotic nematic $\left(\mathrm{N}_{\mathrm{D}}\right)$, and columnar lamellar $\left(\mathrm{Col}_{\mathrm{L}}\right)$. The least ordered of them is the $\mathrm{N}_{\mathrm{D}}$ phase. Discotic molecules in this phase, assimilate to calamitic nematic mesogens, have only orientational ordering relative to the director $(\vec{n})$ of the mesophase, without any positional order. Columnar mesophases are characterized by the feature that their structural unit is a supramolecular ensemble, resembling a stack of coins. They have significant polymorphism associated with the type of two-dimensionally ordered lattice formed by the columns, as well as the degree of ordering of the molecules inside the columns. According to their chemical structure, they can be conditionally divided into four groups: (1) derivatives of six-membered rings with a saturated or unsaturated core, (2) multiring homo- or heterocyclic compounds-super-discs, (3) coordination compounds-discotic metallomesogens and their metal-free analogues, and (4) metallorganyls. The typical representatives of groups 1-3, which are known to be used as lubricants, are shown in Figure 8. 
<smiles>[R]C(=O)Oc1c(O)c(O)c(OC([R])=O)c(OC([R])=O)c1O</smiles>

(a)

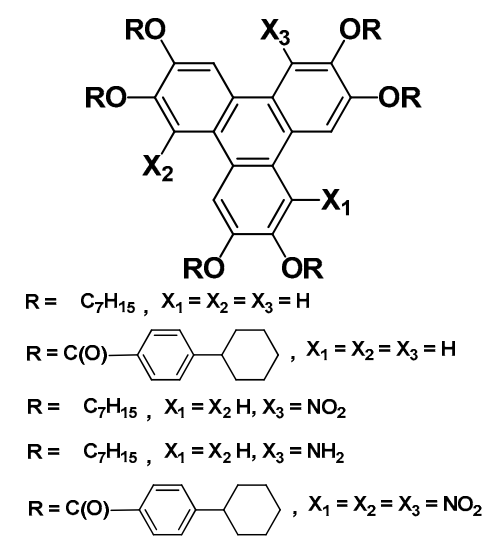

(b)

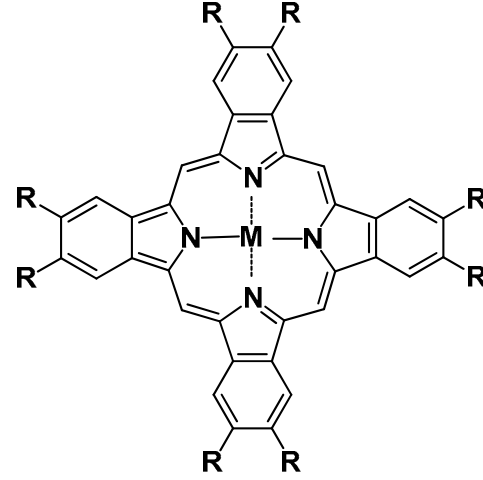

(c)

Figure 8. The typical representatives of discotic mesogens: (a) Hexasubstituted benzenes (group 1);

(b) Triphenylene derivatives (group 2); (c) Phthalocyanine derivatives (group 3) [44].

The first such material was a liquid crystalline derivative of hexaoxytruxen, which displays a columnar phase and was used as a lubricant in a machine element [45]. Later, a new antifriction and antiwear additive to lubricating compositions was proposed [46], it has a columnar supramolecular structure. Then, a series of studies were carried out on the influence of the molecular structure of various discotic mesogens. Among them, columnar mesogens (hexaoxytriphenylene esters as well as their analogues with nitro and amino groups) and discotic nematic mesogens (derivatives of biphenyl and hexa(cyclohexanebenzoate)triphenylene) were reported. As a result, it was found that discotic mesogens displaying columnar mesophases are better used as antifriction additives in heavily loaded friction units, while the mesogens with nematic discotic phase were used as antiwear additives. The effectiveness of the additive is determined by the molecular structure of discotic mesogen. The most favorable features are: (1) the presence of a large number of ester groups $(\geq 6)$ in the central fragment of the discotic mesogen, and (2) a large cross-sectional area of the central fragment of the discotic mesogen molecule per one heteroatom $(\geq 30)$ [47-50].

Discotic mesogens (crown-containing phthalocyanines) have been used as additives to plastic lubricants [51]. It was found that the effectiveness of their use is determined by the following peculiarities: high strength characteristics, increased thermal stability, the ability to structure on the friction surface into columnar ensembles, and the ability to form chemisorbed films. Adsorption-active additives of this type are effective under various friction conditions and are promising as tribological additives to oil and plastic lubricants.

Other columnar mesogens (copper carboxylates) have been investigated as additives to Solidol grease. The dependence of the friction coefficients on the chemical structure of copper carboxylates was studied. All the homologues studied increased the upper temperature limit of the stable operation of the lubricant, being successful thickeners [52].

A large range of works on the use of discotic compounds in tribological processes was carried out using phthalocyanine ( $\mathrm{Pc}$ ) derivatives. This class of compounds has attracted the attention of researchers because they possesses a number of necessary features of triboactive additives: (1) the possibility of structure formation (supramolecular columnar organization) in the bulk of the solution and at the interface; and (2) the ability to thermal decomposition with the formation of chemical lubricating films at the corresponding contact temperature in the friction units. Therefore, Pc derivatives as solid lubricating components can be used both to provide dry friction and as additives to oils [53]. In the region of low additive concentrations, an increase in the number of molecules of heterocyclic compounds and their associates adsorbed by metal friction surfaces occurs. It was suggested that during the initial accumulation of the additive in the boundary layer, adsorption probably occurs due to lateral substituents of Pc. On the one hand, the substituents hold the molecular associates on the surface; on the other hand, they create a flexible "pile" that provides easy gliding, similar to a classic 
surfactant. When the Pc concentration is increased, supramolecular columns are likely to reorient in such a way that the long axes of the molecules are perpendicular to the metal plane, which increases the friction coefficient [53].

Results related to the influence of thermotropic discotic mesogens on the tribological properties of lubricating compositions are summarized in several monographs and reviews $[7,54,55]$.

\section{Lyotropic Mesogens in Tribology}

Lyotropic mesogens (lyomesogens) are amphiphilic molecules or long, rod-shaped molecular and supramolecular structures that form liquid crystalline phases in water and some organic solvents. Molecules of a compound, which is capable of forming a lyotropic mesophase under certain conditions, consist of hydrophilic $\left(-\mathrm{COOH},-\mathrm{OH},-\mathrm{CO}_{2} \mathrm{Na}, \mathrm{SO}_{3} \mathrm{~K},-\mathrm{O}\left(\mathrm{CH}_{2} \mathrm{CH}_{2} \mathrm{O}\right)_{n} \mathrm{H}\right.$, etc.) and lipophilic $\left(-\mathrm{C}_{n} \mathrm{H}_{2 n+1}\right)$ fragments. Rod-shaped lyomesogens include tobacco mosaic virus particles or elongated polypeptide chains, which, being in an ordered state (due to the anisotropy of their shape), impart anisotropic properties to the entire system [56].

A very detailed review regarding lyotropic mesogens and the phases that they form was made by Ekwall [57].

The lyotropic state (as well as the thermotropic one) is characterized by polymorphism (Figure 9), i.e., the ability to form various liquid crystalline phases under changing conditions (concentration, temperature, and other environmental factors). The formation of lyotropic mesophases (lyomesophases) by amphiphilic compounds occurs due to electrostatic (hydrophilic) and electrokinetic (lipophilic) interactions. The first type of such organization is micelles that appear in solution at a certain concentration of amphiphile, which precedes the formation of lyomesophases. Then, with an increase in the concentration of amphiphile, various types of lyotropic mesophases are formed [56].

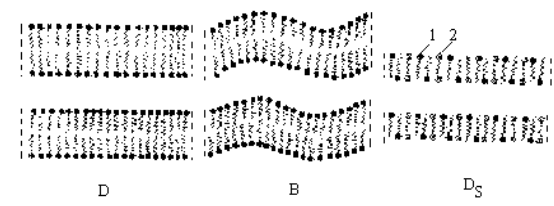

(a)

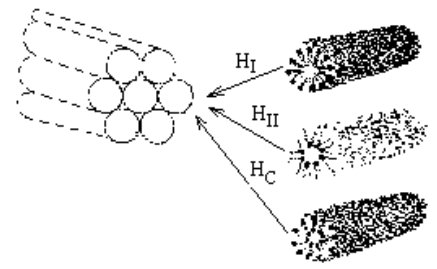

(b)

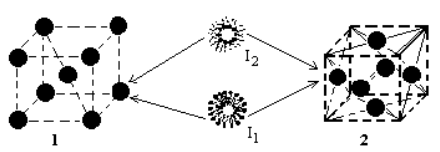

(c)

Figure 9. Different types of lyotropic mesophases: (a) lamellar phases (Lam), (b) hexagonal phases (Hex), and (c) cubic phases (Cub) [56].

\subsection{Ionogenic Lyotropic Mesogens}

The favorite objects of experimenters are ionogenic lyotropic mesogens, including salts of fatty acids, anionic and cationic surfactants, and alkyl polyglucosides [58]. Even small concentrations of surfactant additives (less than $0.1 \mathrm{wt} \%$ ) lead to the formation of boundary ordered layers on shear surfaces. Therefore, the good tribological properties were attributed by the authors of [59-63] to the formation of epitropic mesophases.

The lamellar (layered) phase, an analogue of thermotropic smectic phases, attracted the special attention of tribologists. However, its use was restrained by the negative impact of water on metal conjugation. Friberg [64] showed that the lamellar phase can be formed by surface-active substances (surfactants) also in binary systems with glycerol as the polar solvent. This gave rise to a number of studies of the lamellar phases of binary surfactant systems with non-aqueous solvents, and then to their use in tribology. On the example of 'glycerol-triethanolamine (TEA) - oleic acid (OLA)' systems with a different ratio of OLA and TEA components, it was shown that if the load is sufficiently low and allows saving the LC structure without deformation, then extremely low friction coefficients are achieved (a steel ball ( $\frac{1}{2}$ “diameter) on steel with a sliding rates of $1.7 \times 10^{-2} \mathrm{inch} / \mathrm{s}$ were used). 
In 1991, Pennzoil Products Co. received the first patent for the use of lyotropic phases (in a non-aqueous system) as a lubricant composition [65].

Thus, Friberg [64] made a great contribution to the practical application of lyotropic liquid crystals in tribological processes. However, the lubricating properties of lyotropic systems such as aqueous solutions of soaps and biological fluids (e.g., saliva) were known long before they were recognized as lyotropic mesogens.

An interesting effect was discovered when the friction and wear properties of lamellar phases and their dispersions in water were compared [60]. The authors established that a decrease in viscosity in the latter case leads to rapid relaxation of the system for the formation of new films after the destructive action of two sliding surfaces. It was shown that mixtures of cationic and anionic amphiphiles exhibit the best lubricating properties with a slight excess of any of the surfactants.

Interest in the use of aqueous lyotropic systems for certain friction pairs has persisted all these years, since water-based tribosystems are environmentally friendly. A good example of such lyotropic mesogens are alkyl polyglucosides (APGs). They are biodegradable, exhibit surface activity, and form micellar and lyotropic LC phases in aqueous systems.

In [58], alkyl polyglucosides with different lengths of aliphatic substituents were used as lubricants. Tribological tests were carried out on $1 \%$ solutions. The friction couple elements were balls $6.35 \mathrm{~mm}$ in diameter made of $100 \mathrm{Cr} 6$ and discs $25 \mathrm{~mm}$ in diameter and $8 \mathrm{~mm}$ in thickness made of steel, aluminum oxide $\left(\mathrm{Al}_{2} \mathrm{O}_{3}\right)$, zirconium oxide $\left(\mathrm{ZrO}_{2}\right)$, polyamide 6 (PA6), and poly(methyl methacrylate) (PMMA). It was found that the friction coefficient values decreased 2-, 5-, 2-, 1.5-, and 2.5-fold for the 'steel-steel', 'steel- $\mathrm{Al}_{2} \mathrm{O}_{3^{\prime}}$, 'steel- $\mathrm{ZrO}_{2}$ ' , 'steel-PA6', and 'steel-PMMA' couples, correspondingly, with respect to water. When a steel ball was used, no wear of discs was observed (except for PA6 and PMMA).

The search for similar lubricants led the authors of [66] to use aqueous solutions of maracuja oil, ethoxylated with $60 \mathrm{~mol}$ of ethylene oxide $\left(\mathrm{MEO}_{60}\right)$. It was found that when the concentration of this compound in water is about $60 \%$, a fan-shaped texture is formed that is characteristic of the lyotropic hexagonal phase. Rheological studies performed in this concentration field testified that the flow of this system has the non-Newtonian nature. Tribological studies have shown that this system has good wear resistance in the four-ball tester. Summing up their results, the authors concluded that the studied LLCs could be used because they are characterized by low resistance to motion, low wear, and high load-carrying capacity. In addition, they are safe to use. Their application in the food, pharmaceutical, and cosmetic industries is proposed.

\subsection{Nonionic Lyotropic Mesogens}

In the development of the above-mentioned works, tribological studies of nonionic surfactant additives and their mixtures with ionic surfactants were carried out $[67,68]$. The additives were selected in such a way as to reveal the relationship between tribological characteristics and the molecular weight of the surfactant. Neonol 9/6, Neonol 9/10, and Phenoxol were used as nonionic additives, and the disodium salt of sulfosuccinic acid (DSSA) was used as an ionic surfactant (Table 5). The SMC-2 friction machine was utilized in the study. Materials of friction pairs were Steel 45, Caprolon-B, and RMF-4 $[67,68]$. 
Table 5. Surfactants studied in [67]. DSSA: disodium salt of sulfosuccinic acid.

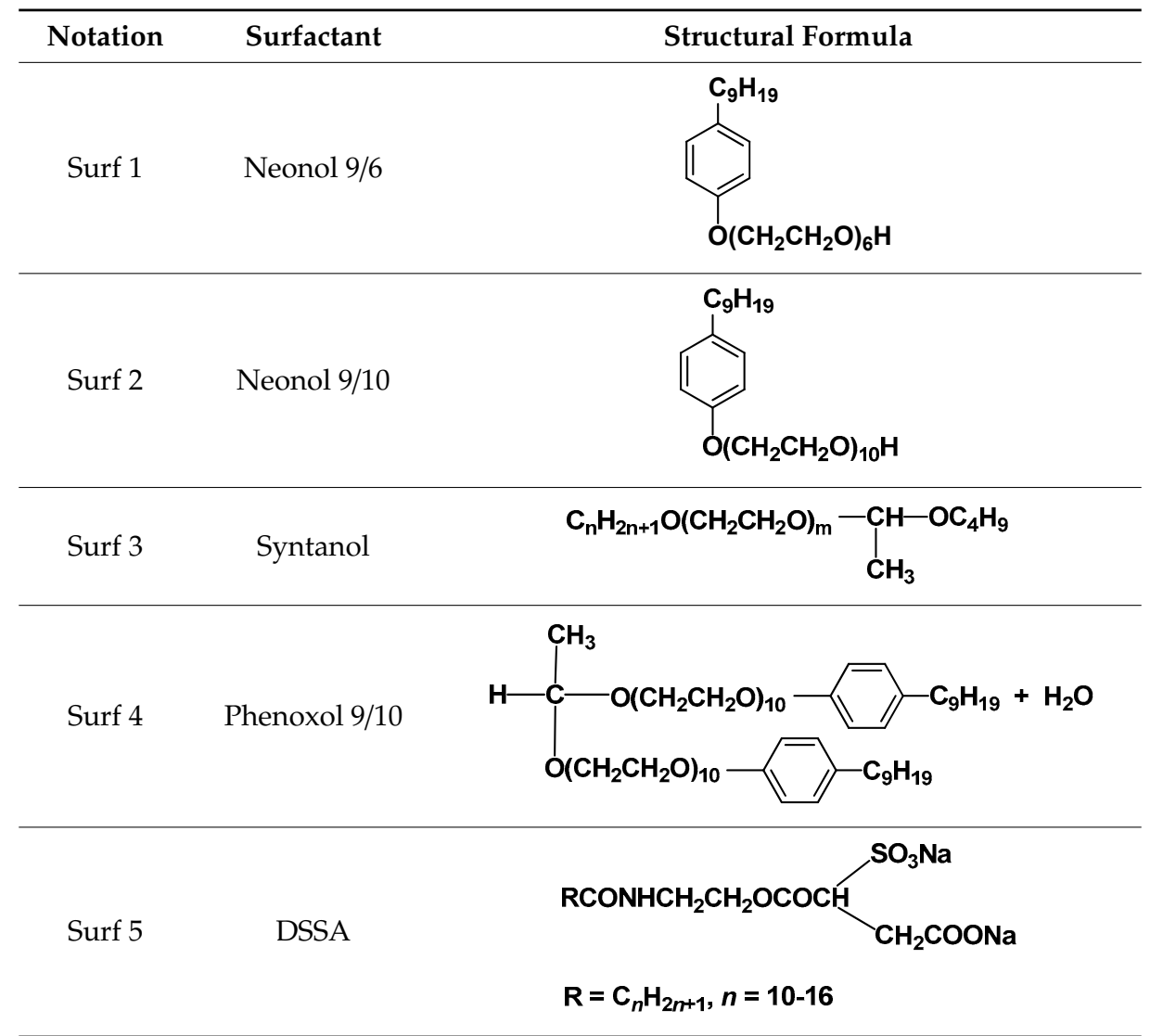

It was shown that the maximum positive effect was observed when the 'ionic surfactant-nonionic surfactant' mixture was introduced in a concentration of $0.5 \mathrm{wt} \%$. In contrast to the individual surfactants of nonionic nature, a significant improvement of antifriction properties of the aqueous system was observed using the mixtures. According to the microscopy data of surface layers, when using surfactant additives, there is no transfer of body matter (RMF-4) to the counter-body (steel 45), which confirms the presence of contact with the boundary lubricant. The influence of mesogenic additives on the wear characteristics of polymeric materials is unambiguous. The greatest effect was achieved when the additive 'Surf $4+$ Surf 5 ' was added to water. Depending on the concentration, the wear value was decreased by $2.5-3$ times.

Lyotropic mesomorphism was obtained not only in mixtures of nonionic and ionogenic surfactants, but in mixtures of nonionic surfactants with ionic liquids, in particular ethylammonium nitrate (EAN). Araos and Warr [69] found cubic, hexagonal, and lamellar phases in these systems. Such a rich polymorphism can also be used in tribological processes.

\subsection{Discotic Heterocyclic Compounds}

A new approach to the use of lubricants with lyotropic mesogens is the application of discotic heterocyclic compounds (or their systems) as additives to classical surfactants in aqueous systems [7,70-72].

Earlier, it was suggested that the complex and anisometric structure of some phthalocyanine derivatives can contribute to the formation of a latent mesomorphic state in solutions. Moreover, in non-aqueous solutions, a number of phthalocyanine derivatives showed columnar lyomesophases (Figure 10). 


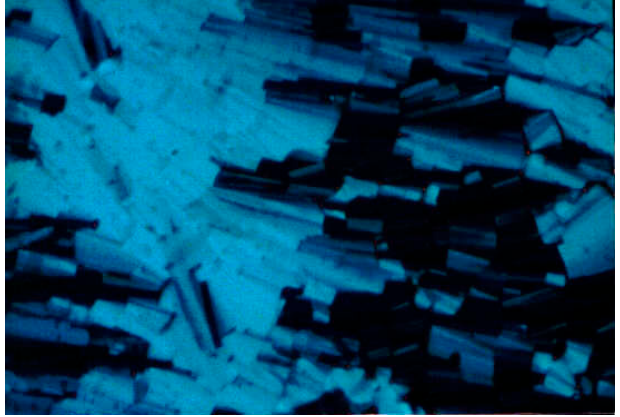

(a)

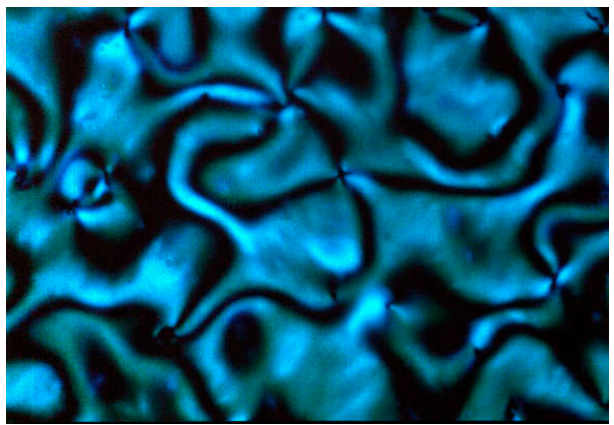

(b)

Figure 10. Microphotographs of mesophase textures of octa(octyloxy)phthalocyanine derivative in binary systems with linear alkanes: (a) with pentadecane, fan-like texture of two-dimensionally ordered columnar lyotropic mesophase, at heating, $\mathrm{T}=112{ }^{\circ} \mathrm{C}$, crossed polarizers, $\times 320$; (b) with decane, Schlieren texture of columnar nematic lyomesophase, on cooling, $\mathrm{T}=50^{\circ} \mathrm{C}$, polarizers crossed, $\times 320$ [17].

Phthalocyanine derivatives on solid friction surfaces can form columnar structures similar to discotic liquid crystals (Figure 1). The friction-sliding process at a constant speed and changing load was studied with the help of the friction machine SMC-2. The structural formulas of studied heterocyclic compounds are shown in Figure 11. The texture of lyotropic mesophase formed by the aqueous solution of Hc3, which is a mixture of Hc1 and Hc2 (1:1), is shown in Figure 12. As can be seen in Figure 13, the composition Hc3 most of all decreases the friction coefficient.

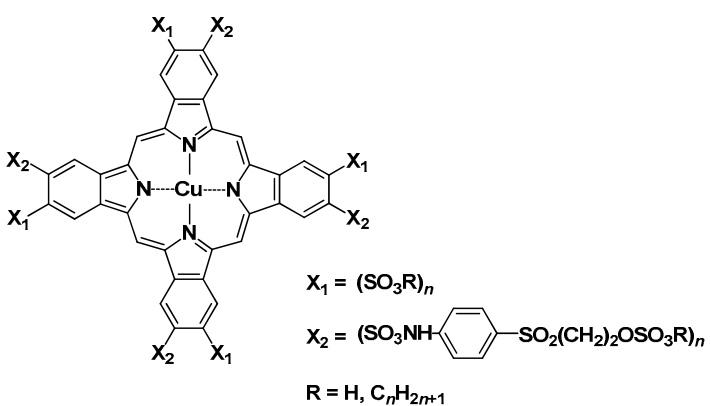

(a)

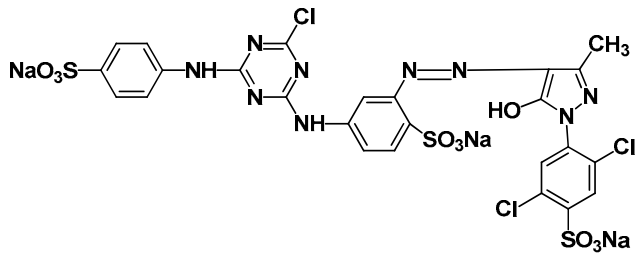

(b)

Figure 11. Formulas of heterocyclic compounds used as triboactive additives in [7]: (a) phthalocyanine derivative-active turquoise dye 2 " 3 " T (Hc1); (b) chromonic lyomesogen—active bright yellow 5 " 3 " (Hc2) [7].

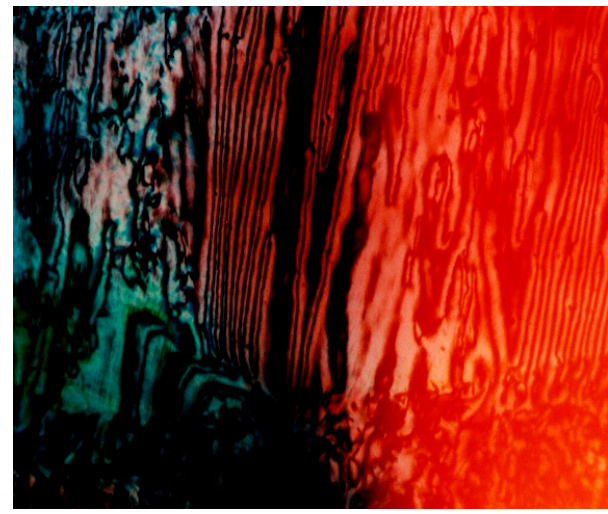

Figure 12. Schlieren-texture of the aqueous solution of the Hc3 mixture after shear deformation in crossed polarizers [7]. 


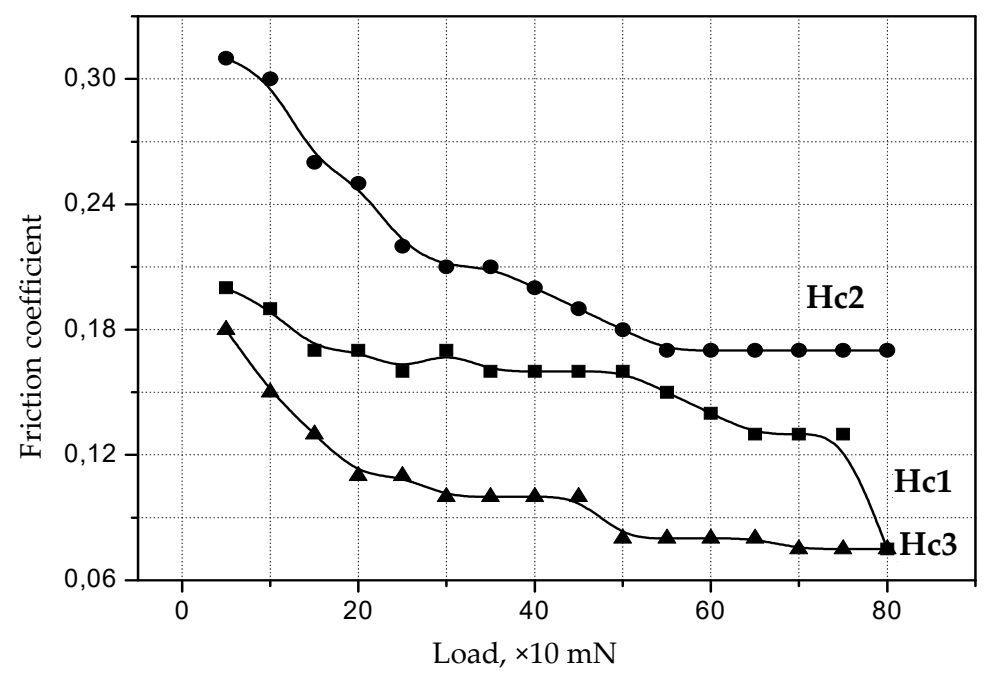

Figure 13. Dependence of the friction coefficient on the contact load of aqueous solutions of heterocyclic compounds: Hc1-Active turquoise dye 2 "3" T; Hc2-Active bright yellow 5 "3"; Hc3-a mixture of Hc1 and Hc2 (1:1) [7].

In general, based on the performed studies, it was concluded that the introduction of heterocyclic additives into aqueous surfactant solutions decreases the friction coefficient [7].

\subsection{Biological Fluids}

During the friction investigation of biological fluids, it was found that they are able to form lyotropic and epitropic mesophases [73]. Currently, there is no doubt that the lyotropic liquid crystal state plays an important role in the functioning of the living systems. The attention of researchers in this direction is mainly concentrated on the study of the structure and functioning mechanisms of biological membranes and their role in the development of pathological processes. However, it turned out that the lyotropic liquid crystalline state also plays an important role in physiology and biomechanics, providing the lubrication function [56,73-75].

A preliminary study of the lubricating properties of synovial fluid, mucous membranes of fish scales, and blood showed that these biological fluids acquire the ability to orientate structural elements under the influence of the active solid surface. This orientation leads to a significant decrease in the friction coefficient and wear [74]. The preferred orientation direction of molecules and its homogeneity in the boundary layer affects macroscopic phenomena as friction, boundary lubricating effect, wedging pressure value, etc. The orientational ordering of polar molecules in the boundary layer caused by the "image forces" action leads to the fact that these layers transform into a metastable liquid crystalline state.

Kupchinov et al. [75] studied human and animal synovial fluid, as well as its lipid extracts and dried preparations. The presence of mesogenic cholesterol derivatives was detected, and the dry preparations showed birefringence during thermopolarization studies. These and other studies have allowed the authors to conclude that the synovial fluid is structurally ordered at a temperature not exceeding $45^{\circ} \mathrm{C}$. Using the Pendulum tribometer, it was shown that the synovial fluid with a higher concentration of cholesterol esters has better antifriction properties.

These works were further developed in $[25,76,77]$ both in the direction of the concept of synovial fluid influence and the creation of artificial compositions-synovial fluid substitutes.

Along with this, attempts have been made to a theoretical description of joint lubrication. The idea of Kupchinov about the liquid crystal state of synovial fluid was supported. However, the model of liquid crystalline structures has also been advanced with regard to articular cartilage and other connective tissues $[78,79]$. 
The replacement of large joints with artificial prostheses is a great achievement of orthopedics, but it raised the issue of the friction and wear processes in these systems. Under experimental conditions (in vitro), mostly excellent tribological data were obtained, but they were not confirmed by practice (in vivo) [80].

Recently, attempts have been made to create liquid crystalline compositions as lubricants for artificial joints. Thus, Ruiz-Fernández et al. [81] proposed a composition containing tetradecyltrimethylammonium bromide (TTAB), decanol $(\mathrm{DeOH})$, sodium bromide $(\mathrm{NaBr})$, and a natural mixture of lipids in water. This system had a viscosity range two times wider than other similar systems. A wide viscosity range does not affect the presence of a nematic discotic phase, which promotes lubrication processes. In the experiments, ceramic-on-ceramic $(\mathrm{CoC})$ and ceramic-on-polyethylene $(\mathrm{COP})$ implants were used. Since four biological components are most represented in the synovial fluid-hyaluronic acid (HA), albumin mucinous glycoproteins (mainly lubricin), and globulin - therefore, the variation of these components was the subject of the tribological experiments. It was found in experiments that the lubricant fluid composition LO2 (manufactured by BSF) shows the highest viscosity and the least wear on the surfaces of friction pairs. This composition contains various types of proteins and lipids, among which HA plays a major role in the viscosity of fluids.

Another important biological fluid is saliva, which also performs the function of lubricant. Mucin glycoproteins in saliva make up the bulk of its dry residue. Due to the negative charge, the molecules of the glycoproteins have a rigid unfolded comb-like structure, which significantly increases the viscosity of saliva. It has a high film-forming ability, and the ions contained in the saliva, in particular the thiocyanate ion, contribute to the crosslinking of biopolymers.

For a number of polypeptides and enzymes (which are proteins by their nature), it was established that they are liquid crystalline [82]. The liquid crystalline state leads to a significant ordering of structural elements of a multicomponent system. Since saliva moistens food, it is natural to assume that the movement of food in the mouth and esophagus is accompanied by friction, and a mixture of saliva and the mucous membrane secretion of the esophagus surface acts as a lubricant. The microscopic observations showed $[73,83,84]$ that in the process of saliva drying, the tree-like structure is formed (Figure 14). It is made of aggregates that are close in shape to a square, with a side length of $16.2 \pm 2.7 \times 10^{-3} \mathrm{~cm}$. As a rule, the aggregates merge when they approach each other and form continuous filaments with dendritic growth.

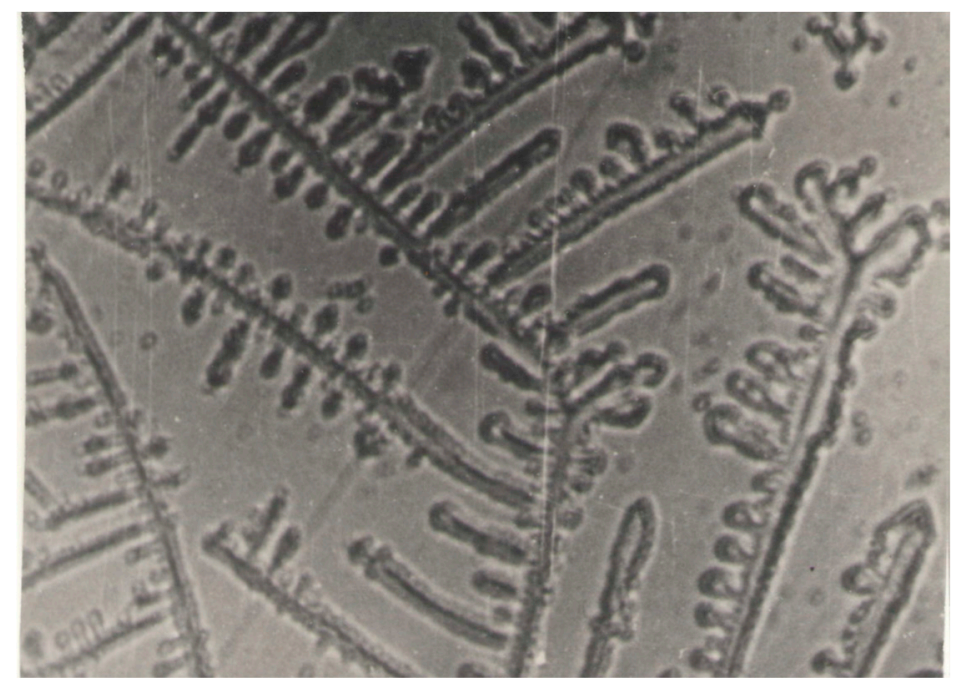

Figure 14. Saliva preparation after drying. Polarizers are parallel. $\times 200$.

In crossed polarizers, on the dark field of dried saliva, luminous dots and rod-shaped small formations are visible. They change their light transmission intensity and color when the microscope stage is rotated. 
Native saliva does not exhibit birefringence. However, after its friction between two glasses, a different polarization microscopic picture is observed. In this case, characteristic elongated birefringent structures are formed, indicating an ordered liquid crystalline state (Figure 15).

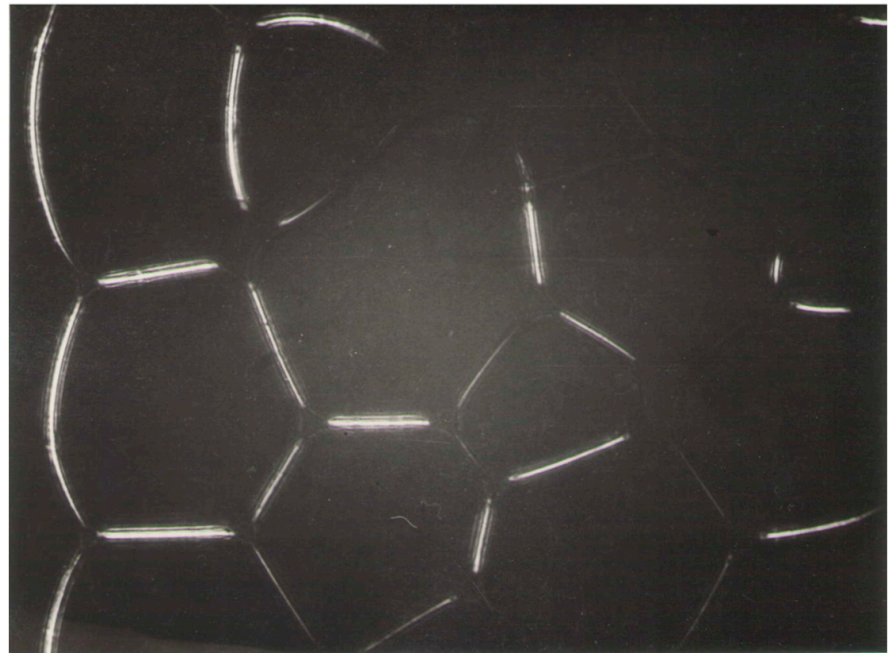

Figure 15. Saliva preparation after friction with twisting. Polarizers are crossed. $\times 200$.

These structures are preserved for 18-36 h, and then, in the process of drying, the birefringent lines begin to crush into separate point areas, which are reminiscent of the shape of the tree-like structure of dry saliva. Obviously, in this case of saliva, there is an interesting example of the lyotropic liquid crystalline state formation in the process of friction. The friction determines the uniform orientation of saliva biopolymers.

Such a labile mechanism of the lubricant transition from an unoriented state to a uniformly oriented state can be used in the development of technical lubricants. These lubricants can be applied to reduce the friction of interacting elastomers, reduce the hydrodynamic resistance when transporting substances through pipes made of polymeric materials, and also to study the effect of salivary fluid on the friction and wear of tooth enamel, the surfaces of dentures, and joint prostheses.

Thus, biological lubricants containing glycoproteins and proteins, even with a small amount of dry residue, provide the formation of epitropic lyomesophases, which give a high efficiency to the lubrication process. Glycoproteins, which are the main dry residue of saliva, make up 1-2\% by weight. The metastable liquid crystalline state that was found in saliva, in combination with the previously obtained information [74] on the induced liquid crystalline state of the synovial fluid and mucous membrane of fish scales, gave one reason to conclude that the mechanism of sliding friction of the biological media containing polymers and large percentage of water is of the same type. This conclusion was confirmed in the works of Vazina et al. [85], who established that the secretion of the glands of the gastrointestinal tract also has liquid crystalline ordering. The above-mentioned data allowed us to obtain a new lubricant-cooling technological agent [86].

\section{Conclusions}

This review of the use of thermotropic and lyotropic mesogens as smart materials in tribological processes shows the great promise of these materials. The outlined data do not exhaust the entire palette of modern research directions in the field of application of liquid crystals in tribology. At present, the desire/tendency to miniaturize friction units and the task of developing environmentally friendly lubricants - as well as highly effective antifriction, antiwear, antiseize additives to them-stimulate the development of theoretical studies. In particular, this review includes investigations in the field of boundary lubrication, studying the relationship between the structure of molecules, the rheological and tribological properties of mesogens, and the development of materials with programmable 
properties. Experiments are being performed on LC compositions with non-mesogens, nanoparticles, carbon nanostructures, and ionic liquids. The supramolecular structuring underlying the formation of mesophases, including epitropic ones, becomes a key mechanism for creating effective lubricant compositions in the 21st century.

The establishment of the important role of the liquid crystalline state in tribological processes has led to the use of new compositions of lubricating and cutting fluids in both metal processing and living systems. Further research on biolubricants exhibiting extremely low values of friction and wear can lead to the creation of fundamentally new lubricants for industrial use.

Funding: This research was funded by the RFBF, grant number 18-29-19150_mk and by the Ministry of Education and Science of the Russian Federation in the framework of the state task for Ivanovo State University, grant number 16.1037.2017/4.6.

Conflicts of Interest: The authors declare no conflict of interest.

\section{References}

1. Usol'tseva, N.V.; Akopova, O.B. Tribology and Mesomorphism. In Physics, Chemistry and Mechanics of Tribosystems, Interuniversity Collection of Scientific Papers; Latyshev, V.N., Ed.; Ivanovo State University: Ivanovo, Russia, 2011; pp. 14-23. (In Russian)

2. Myshkin, N.K.; Petrokovec, M.I. Friction, Lubrication, Wear. Physical Fundamentals and Technical Applications of Tribology; FIZMATLIT: Moscow, Russia, 2007; p. 368. ISBN 978-5-9221-0824-9. (In Russian)

3. Stribeck, R. Die wesentlichen Eigenschaften der Gleit-und Rollenlager. Z. Ver. Dtsch. Ing. 2002, 36, 1341-1348.

4. Minami, J. Ionic Liquids in Tribology. Molecules 2009, 14, 2286-2305. [CrossRef] [PubMed]

5. Carrion, F.-J.; Martinez-Nicolas, G.; Iglesias, P.; Sanes, J.; Bermudez, M.-D. Liquid Crystals in Tribology. Int. J. Mol. Sci. 2009, 10, 4102-4115. [CrossRef] [PubMed]

6. Shen, M.; Luo, J.; Wen, S.; Yao, J. Nanotribological properties and mechanisms of the liquid crystal as an additive. Chin. Sci. Bull. 2001, 46, 1227-1232. [CrossRef]

7. Berezina, E.V. Phthalocyanine Derivatives as Additives to Lubricating Compositions; Ivanovo State University: Ivanovo, Russia, 2007; p. 240. ISBN 5-7807-0614-X. (In Russian)

8. Gao, Y.; Jiang, Y.; Hu, W.; Jiang, H.; Li, J. Cholesteric liquid crystals as oil based lubricant additives: Effect of mesogenic phases and structures on tribological characteristics. Langmuir 2019, 35, 6981-6992. [CrossRef]

9. Deryagin, B.V. Research in Surface Forces: Surface Forces in Thin Films and Disperse Systems; Springer: Moscow, Russia, 1972; p. 326. (In Russian)

10. Sonin, A.S.; Frenkel, V.Y. Vsevolod Konstantinovich Frederiksz: 1885-1944; FIZMATLIT: Moscow, Russia, 1995; p. 176. ISBN 5-02-015179-3. (In Russian)

11. Comstock, M.J. Tribology and the Liquid Crystalline State; ACS Symposium Series; Biresaw, G., Ed.; American Chemical Society: Washington, DC, USA, 1990; Volume 441, p. 133.

12. Latyshev, V.N.; Karabanov, V.B.; Chaikovsky, V.M.; Chistyakov, I. Cutting Fluid for Machining of Metals. SU No. 601304, 27 April 1978. (In Russian).

13. Latyshev, V.N.; Korotkov, V.B.; Godlevskiy, V.A.; Volkov, V.F.; Usol'tseva, N.V. Antifriction Additive for Oils. SU No. 1086009, 15 April 1984. (In Russian).

14. Latyshev, V.N.; Korotkov, V.B.; Godlevskiy, V.A.; Alexandrov, A.I.; Usol'tseva, N.V.; Volkov, V.F. Cutting Fluid for Machining of Metals. SU No. 1149622, 22 December 1983. (In Russian).

15. Latyshev, V.N.; Lazuk Yu, N.; Usol'tseva, N.V. Liquid Crystals and Their Practical Application. In Proceedings of the Republican Conference, Baku, Azerbaijan, 20 January 1990; pp. 37-38. (In Russian)

16. Goodby, J.W.; Gray, G.W. Guide to the Nomenclature and Classification of Liquid Crystals. In Handbook of Liquid Crystals, 1st ed.; Demus, D., Goodby, G., Gray, G.W., Spiess, H.-W., Vill, V., Eds.; Wiley-VCH: Weinheim, Germany; New York, NY, USA; Chichester, UK; Singapore, 1998; Volume 1, pp. 17-23.

17. Usol'tseva, N.V.; Akopova, O.B.; Bykova, V.V.; Smirnova, A.I.; Pikin, S.A. Liquid Crystals: Discotic Mesogens, 1st ed.; Usol'tseva, N.V., Ed.; Ivanovo State University: Ivanovo, Russia, 2004; p. 546. ISBN 5-7807-0458-9. (In Russian)

18. Usol'tseva, N.V. Lyotropic Liquid Crystals: Chemical and Supramolecular Structure; Ivanovo State University: Ivanovo, Russia, 1994; p. 220. ISBN 5-230-02212-4. (In Russian) 
19. Volkmar, V.; Galewski, Z. LiqCryst 5.0. Database of Liquid Crystals; LCI Publisher: Hamburg, Germany, 2010.

20. Cognard, J. Lubrication with Liquid Crystals. In Tribology and the Liquid Crystalline State; ACS Symposium Series; Biresow, G., Ed.; American Chemical Society: Washington, DC, USA, 1990; Volume 441, pp. 1-47.

21. Mori, S.; Iwata, H. Relationship between tribological performance of liquid crystals and their molecular structure. Tribol. Intern. 1996, 29, 35-39. [CrossRef]

22. Nakano, K. Tribology of Liquid Crystals. Chem. Ind. 2004, 55, 460-465.

23. Amann, T.; Kailer, A. Relationship between ultralow friction of mesogenic-like fluids and their lateral chain length. Tribol. Lett. 2011, 41, 121-129. [CrossRef]

24. Wažyńska, D.; Okowiak, J.A. Tribological properties of nematic and smectic liquid crystalline mixtures used as lubricants. Tribol. Lett. 2006, 24, 1-5. [CrossRef]

25. Ermakov, S.F.; Rodnenkov, V.G.; Beloenko, E.D.; Kupchinov, B.I. Liquid Crystals in Engineering and Medicine; Asap: Minsk, Belarus; ChePo: Moscow, Russia, 2002; p. 411. ISBN 985-6572-66-5, 5-88711-175-5. (In Russian)

26. Demus, D.; Demus, H.; Zaschke, H. Flussige Kristalle in Tabellen; VEB Deut.: Leipzig, Germany, 1974.

27. Syrbu, S.A.; Novikov, V.V.; Burchenkov, K.S.; Fedorov, M.S. New Functional Nanostructured Materials for Tribosystems Based on Nematogen Systems. In Organic and Hybrid Nanomaterials: Production, Research, Application: Monograph; Razumov, V.F., Kluev, M.V., Eds.; Ivanovo State University: Ivanovo, Russia, 2019; pp. 307-337. (In Russian)

28. Buyanovsky, A.I.; Zacharov, S.M. Lubrication. In Friction, Wear and Lubrication (Tribology and Tribotechnology); Chichivadze, A.V., Ed.; Mashinostroenie: Moscow, Russia, 2003; pp. 184-248. (In Russian)

29. Kupchinov, B.I.; Ermakov, S.F.; Parkalov, V.P.; Rodnenkov, V.G. Study of the influence of mesogenic lubricant additives on the kinetics of the friction coefficient. Dokl. Natl. Acad. Sci. Belarus 1989, 33, 340-343. (In Russian)

30. Bermúdez, M.D.; Martinez-Nicolás, G.; Carrion-Vilches, F.J. Tribological properties of liquid crystals as lubricant additives. Wear 1997, 212, 188-194. [CrossRef]

31. Vektris, V.; Mokshin, V. Tribological research of industrial oil with liquid-crystal additives. Mater. Sci. 2008, 44, 730-734. [CrossRef]

32. Latyshev, V.N.; Syrbu, S.A.; Novikov, V.V.; Kolbashov, M.A. Reological Properties of Lubricating Oils with the Additives of Cholesteric Liquid Crystals. Liq. Cryst. Appl. 2008, 3, 52-59.

33. Berezina, E.V.; Korsakov, M.N.; Pavlov, A.S.; Bykova, V.V.; Usol'tseva, N.V. Curve currents of viscous lubricants with liquid crystal additives. Liq. Cryst. Appl. 2010, 2, 85-96.

34. Berezina, E.V.; Korsakov, M.N.; Pavlov, A.S.; Usol'tseva, N.V. Viscometry of plastic lubricants with mesogenic additives. Fiz. Him. Mekhanika Tribosistem 2009, 8, 171-173. (In Russian)

35. Rebinder, P.A. Surface Phenomena in Disperse Systems. Physicochemical Mechanics; Nauka: Moscow, Russia, 1979; p. 428. (In Russian)

36. Ermakov, S.F.; Myshkin, N.K. Liquid-Crystal Nanomaterials. Tribology and Applications; Springer Intern Publishing AG: Basel, Switzerland, 2018; Volume 267.

37. Popova, M.N.; Zharova, M.A.; Usol'tseva, N.V.; Smirnova, A.I.; Bogdanov, V.S. Rheological and tribological properties of industrial oil with mesogenic additives and carbon nanotubes. Liq. Cryst. Appl. 2014, 14, 52-61.

38. Usol'tseva, N.V.; Smirnova, M.V.; Kazak, A.V.; Smirnova, A.I.; Bumbina, N.V.; Il'in, S.O.; Rozhkova, N.N. Reological Characteristics of Different Carbon Nanoparticles in Cholesteric Mesogen Dispersions as Lubricant Coolant Additives. J. Frict. Wear 2015, 36, 380-385. [CrossRef]

39. Usol'tseva, N.V.; Yakemseva, M.V. Mesogens and Polymers in Systems with Carbon Nanoparticles. In Organic and Hybrid Nanomaterials: Trends and Prospects: Monograph; Razumov, V.F., Kluev, M.V., Eds.; Ivanovo State University: Ivanovo, Russia, 2013; pp. 228-280. (In Russian)

40. De Jeu, W.H. Physical Properties of Liquid Crystalline Materials; Gordon and Breach Science Publishers: New York, NY, USA; London, UK; Paris, France, 1980; 133p.

41. Yakemseva, M.V.; Usol'tseva, N.V. Viscoelastic properties of cholesteric liquid crystal—Multiwall carbon nanotubes composite. Liq. Cryst. Appl. 2013, 2, 90-94.

42. Usol'tseva, N.V.; Smirnova, M.V.; Sotsky, V.V.; Smirnova, A.I. Physical properties of cholesteric liquid crystals-Carbon nanotube dispersions. J. Phys. Conf. Ser. 2014, 558, 012003. [CrossRef]

43. Ali, I.; Bashneer, A.A.; Kucherova, A.; Memetov, N.; Pasko, T.; Ovchinnikov, K.; Pershin, V.; Kuznetsov, D.; Galunin, E.; Grachev, V.; et al. Advances in carbon nanomaterials as lubricants modifiers. J. Mol. Liq. 2019, 279, 251-266. [CrossRef] 
44. Usol'tseva, N.V.; Akopova, O.B. Molecular Structure of Organic Compounds and Their Thermotropic Mesomorphism. In Liquid Crystals: Discotic Mesogens, 1st ed.; Usol'tseva, N.V., Ed.; Ivanovo State University: Ivanovo, Russia, 2004; pp. 10-96. ISBN 5-7807-0458-9. (In Russian)

45. Eidenschink, R. Mechanical Component. Patent No 3821855.0 FRG, 29 June 1988.

46. Akopova, O.B.; Bobrov, V.I.; Tuneva, G.A. Anti-friction and Antiwear Lubricant Additive. SU No. 1664818, 22 March 1991.

47. Usol'tseva, N.V.; Akopova, O.B.; Bykova, V.V. Physico-Chemical Properties of Discotic Mesogens that Determine Their Use. In Liquid Crystals: Discotic Mesogens, 1st ed.; Usol'tseva, N.V., Ed.; Ivanovo State University: Ivanovo, Russia, 2004; pp. 490-538. ISBN 5-7807-0458-9. (In Russian)

48. Akopova, O.B.; Zemtsova, O.V.; Kotovich, L.N.; Lapshin, V.B. Tribological Characteristics of Triphenylene Derivatives with Columnar and ND Mesophases. In Vestnik IvGU; Ivanovo State University: Ivanovo, Russia, 2001; pp. 71-75. (In Russian)

49. Akopova, O.B.; Gribova, L.K.; Zemtsova, O.V.; Savchenko, V.E.; Usol'tseva, N.V. Application of quartz resonators for research of apolar and polar hexaalkoxytriphenylene derivatives phase transitions. In Proceedings of the XIV Conference on Liquid Crystals, Zakopane, Poland, 1 June 2001; p. 23.

50. Zemtsova, O.V.; Akopova, O.B.; Usol'tseva, N.V.; Erdelen, C.H. Columnar mesomorphism of the mixed substituted apolar triphenylenes. Prognosis and experimental data. Mol. Cryst. Liq. Cryst. 2001, 364, 625-634. [CrossRef]

51. Akopova, O.B.; Logacheva, N.M.; Baulin, V.E.; Tsivadze, A.Y.; Terentiev, V.V.; Subbotin, K.V. Investigation of tribological properties of discotic mesogens-Derivatives of phthalocyanine containing crown ether fragments. In Proceedings of the VII International Scientific Conference "Lyotropic Liquid Crystals and Nanomaterials" Together with the Symposium "Success in the Study of Thermotropic Liquid Crystals" (the Vth Chistyakov's Readings), Ivanovo, Russia, 16-18 December 2009; p. 93. (In Russian).

52. Latyshev, V.N.; Terentiev, V.V.; Akopova, O.B.; Subbotin, K.V. The use of copper carboxylates as additives for solidol. In Proceedings of the International Scientific Conference "Actual Problems and Prospects for the Development of Agriculture", Ivanovo, Russia, 26 August 2009; Volume 2, pp. 95-96. (In Russian).

53. Berezina, E.V.; Godlevskiy, V.A. Mesogenic Compounds as Triboactive Additives. In Achivements of Liquid Crystals Research, 1st ed.; Usol'tseva, N.V., Ed.; Ivanovo State University: Ivanovo, Russia, 2007; pp. 80-94. (In Russian)

54. Akopova, O.B.; Usol'tseva, N.V. Discotic Mesogens: From Monomers to Polymers and Dendrimers; Ivanovo State University: Ivanovo, Russia, 2010; p. 112. (In Russian)

55. Usol'tseva, N.V.; Bykova, V.V.; Akopova, O.B. Achivements of Liquid Crystals Research, 1st ed.; Usol'tseva, N.V., Ed.; Ivanovo State University: Ivanovo, Russia, 2007; 100p, ISBN 5-7807-0655-7. (In Russian)

56. Usol'tseva, N.V. Chemical characterization, biological and medical significance of lyotropic liquid crystals. Zhurnal Vsesoyuznogo Him. Obs. Mendeleeva 1983, 28, 36-45. (In Russian)

57. Ekwall, P. Composition, Properties of Liquid Crystalline Phases in Systems of Amphiphilic Compounds. In Advances in Liquid Crystals; Brown, G.H., Ed.; Academic Press: New York, NY, USA; San Francisco, CA, USA; London, UK, 1975; Volume 1, pp. 1-142.

58. Sułek, M.W.; Ogorzałek, M.; Wasilewski, T.; Klimaszewska, E. Alkyl Polyglucosides as components of water based lubricants. J. Surfactants Deterg. 2013, 16, 369-375. [CrossRef] [PubMed]

59. Ma, C.S.; Li, G.Z.; Shen, Q.A. Study of lyotropic liquid crystal in lubrication on aluminium alloy surfaces. J. Dispers. Sci. Technol. 1999, 20, 1025-1030. [CrossRef]

60. Boschkova, K.; Elvesjo, J.; Kronberg, B. Frictional properties of lyotropic liquid crystalline mesophases at surfaces. Colloid Surf. A Physicochem. Eng. Asp. 2000, 166, 67-77. [CrossRef]

61. Latyshev, V.N.; Lazuk, Y.N.; Usol'tseva, N.V. Compositions based on lyotropic mesogens and their practical application in tribology. In Proceedings of the Republic Conference "Liquid Crystals and Their Application"; Union of Soviet Socialist Republics: Baku, USSR, 1990; pp. 37-38. (In Russian)

62. Bobrov, V.I.; Krasikov, N.N. Birefringence resulting from friction in thin surfactant layers in a solid state. Trenie Isnos 1981, 2, 545-548. (In Russian)

63. Levchenko, V.A. Epitropic liquid crystals-A new liquid phase. J. Mol. Liq. 2000, 85, 197-210. [CrossRef]

64. Frieberg, S.E.; Ward, A.J.; Gunsel, S.; Lockwood, F.E. Lyotropic Liquid Crystals in Lubrication. In Tribology and the Liquid-Crystalline State; ACS Symposium Series; Bireslaw, G., Ed.; American Chemical Society: Washington, DC, USA, 1990; Volume 441, pp. 101-110. 
65. Pennzoil Products Company. Pennzoil Products Company. Non-Aqueous Lamellar Liquid Crystalline Lubricants. U.S. Patent No. 4,999,122, 30 December 1988.

66. Sułek, M.W.; Bak-Sowinska, A. New Ecological Lubricants on the Basis of Lyotropic Liquid Crystals Formed by Solutions of Maracuja Oil Ethoxylate. Ind. Eng. Chem. Res. 2013, 52, 16169-16174. [CrossRef]

67. Shilov, M.A. Investigation of self-organization mechanism of non-ionic surface-active substances and their combinations with ionic ones in water-lubricating friction junctions. Liq. Cryst. Appl. 2011, 1, 57-64.

68. Berezina, E.V.; Shilov, M.A. Structured gels as lubricant and coolant mixtures in drilling. Russ. Eng. Res. 2011, 31, 91-93. [CrossRef]

69. Araos, M.U.; Warr, G.G. Self-Assembly of Nonionic Surfactants into Lyotropic Liquid Crystals in Ethylammonium Nitrate, a Room-Temperature Ionic Liquid. J. Phys. Chem. B 2005, 109, 14275-14277. [CrossRef] [PubMed]

70. Berezina, E.V. Improving the Workability of Steels and Alloys Using Synthetic Aqueous Lubricant-Cooling Agent with New Triboactive Additives. Ph.D. Thesis, Ivanovo State University, Ivanovo, Russia, 1992.

71. Berezina, E.V.; Godlevskiy, V.A. On the use of aqueous solutions of phthalocyanine as triboactive additives to technological media for metal cutting. Bull. Acad. Sci. 1991, 55, 1757-1759. (In Russian)

72. Berezina, E.V.; Godlevskiy, V.A.; Usol'tseva, N.V.; Chrunov, A.A. The study of the viscosity concentration dependences of aqueous solutions of dyes. Liq. Cryst. Appl. 2004, 3, 63-71.

73. Usol'tseva, N.V.; Latyshev, V.N.; Bobrov, V.I.; Pischasova, G.K. On the Liquid Crystalline State of Saliva as a Lubricant Fluid. In Frictional Interaction of Solids Taking into Account the Medium; Ivanovo State University: Ivanovo, Russia, 1982; pp. 148-151. (In Russian)

74. Barchan, G.P. Liquid crystalline state of interfacial layers at sliding. Doklady Natl. Acad. Sci. Belarus 1981, 258, 86-88. (In Russian)

75. Kupchinov, B.I.; Ermakov, S.F.; Rodnenkov, V.G.; Bobrysheva, S.N.; Beloenko, E.D.; Kestelman, V.N. Role of liquid crystals in the lubrication of living joints. Smart Mater. Struct. 1993, 2, 7-12. [CrossRef]

76. Kupchinov, B.I. Tribological aspects of joint functioning. Trenie Isnos 1989, 10, 1013-1018. (In Russian)

77. Kupchinov, B.I.; Ermakov, S.F.; Beloenko, E.D. Biotribology in Synovial Joints; NANB-MZRB: Minsk, Belarus, 1997.

78. Szwajczak, E.; Kucaba-Pietal, A. Liquid crystalline properties of synovial fluid. Eng. Trans. 2001, 49, 315-358.

79. Dowson, D. Biotribology of Natural and Replacement Synovial Joints. In Biomechanics of Diarthrodial Joints; Mow, V.C., Woo, S.L.-Y., Ratcliffe, A., Eds.; Spribger: Berlin, Germany, 1990; Volume 2, pp. 305-345.

80. Ghosh, S.; Choudhury, D.; Roy, T.; Moradi, A.; Masjuki, H.H.; Pingguan-Murphy, B. Tribological performance of the biological components of synovial fluid in artificial joint implants. Sci. Technol. Adv. Mater. 2015, 16, 045002. [CrossRef]

81. Ruiz-Fernández, A.R.; Tejos, R.; Ahumada-Gutierrez, H.; Muñoz-Gacitúa, D.; Martínez-Cifuentes, M.; Araya-Maturana, R.; Weiss-López, B.E. Characterisation of a new nematic lyotropic liquid crystal with natural lipids from soybean. Mol. Phys. 2018, 117, 158-166. [CrossRef]

82. Papkov, S.P.; Kulichikhin, V.G. The Liquid Crystalline State of Polymers; Chimia: Moscow, Russia, 1977 ; p. 240. (In Russian)

83. Usol'tseva, N.V.; Bobrov, V.I.; Shabishev, L.S.; Pischasova, G.K. Polarization-Microscopic Analysis of Biological Fluid Containing Friction-Oriented Glycoproteins. In Abstract Book of the 1st All-Union Symposium on the Liquid Crystalline State of Polymers; USSR Academy of Sciences, Scientific Council on Macromolecular Compounds: Suzdal, Russia, 1982; pp. 96-97. (In Russian)

84. Usol'tseva, N.V. Molecular and Supramolecular Structure of Lyomesogens and Properties of Lyomesophases. Ph.D. Thesis, Leningrad State Univerisity, Leningrad, Russia, 1990. (In Russian).

85. Vazina, A.A.; Eliakova, L.A.; Skopinov, S.A.; Chernoborodova, S.V.; Yakovleva, S.V. Lyotropic Mesomorphism of Glucanes. In Abstract Book of the VIth All-Union Conference on Liquid Crystals and Their Application; Chernihiv National Pedagogical University named after T.G. Shevchenko: Chernigov, Russia, 1988; Volume 3, p. 427. (In Russian)

86. Lazuk, Y.N.; Latyshev, V.N.; Usol'tseva, N.V.; Kolesnikov, N.D. Lubricant-Cooling Agent. SU No 1692814A1, 11 October 1989. (In Russian).

(C) 2019 by the authors. Licensee MDPI, Basel, Switzerland. This article is an open access article distributed under the terms and conditions of the Creative Commons Attribution (CC BY) license (http://creativecommons.org/licenses/by/4.0/). 